Portland State University

PDXScholar

Fall 12-2-2014

\title{
Assessing Generic and Program-Specific Dose- Response Relations Between Engagement in Contemplative Practices and Reductions in Teachers' Occupational Stress and Burnout
}

Jessica Leigh Harrison

Portland State University

Follow this and additional works at: https://pdxscholar.library.pdx.edu/open_access_etds

Part of the Psychology Commons, and the Teacher Education and Professional Development Commons

Let us know how access to this document benefits you.

\section{Recommended Citation}

Harrison, Jessica Leigh, "Assessing Generic and Program-Specific Dose-Response Relations Between Engagement in Contemplative Practices and Reductions in Teachers' Occupational Stress and Burnout" (2014). Dissertations and Theses. Paper 2107.

https://doi.org/10.15760/etd.2105

This Thesis is brought to you for free and open access. It has been accepted for inclusion in Dissertations and Theses by an authorized administrator of PDXScholar. Please contact us if we can make this document more accessible: pdxscholar@pdx.edu. 
Assessing Generic and Program-Specific Dose-Response Relations Between Engagement in Contemplative Practices and Reductions in

Teachers' Occupational Stress and Burnout

by

Jessica Leigh Harrison

A thesis submitted in partial fulfillment of the requirements for the degree of

\author{
Master of Science \\ in \\ Psychology
}

Thesis Committee:

Robert W. Roeser, Chair

Andrew J. Mashburn

Ellen A. Skinner

Portland State University

2014 


\begin{abstract}
Teaching is a stressful, uncertain, and emotionally laden profession (Chaplain, 2008; Farber, 1999; Johnson et al, 2005). One approach to reduce psychological distress and improve well-being in teachers is through the use of mindfulness-based stress reduction (MBSR) programs. While MBSR programs have been shown in several studies to be effective with regard to improving well-being in teachers, little research has been done to date examining the relationship between program dose and outcomes. This study examines the relationship between both generic and program-specific dose and outcomes of stress and burnout. Results showed some evidence that generic yoga frequency is related to outcomes. No significant relationships between program-specific dose and outcomes were found. Directions for future research are discussed.
\end{abstract}




\section{Acknowledgements}

This project would not have been possible without the support of many people. Many thanks to my adviser, Robert W. Roeser, for his numerous rounds of feedback, and his continuous mentorship. Also thanks to my committee members, Andrew Mashburn and Ellen Skinner, for their guidance and support. Thanks as well to my fellow program members for their encouragement and support. 


\section{Table of Contents}

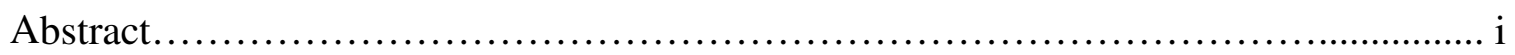

Acknowledgements........................................................ ii

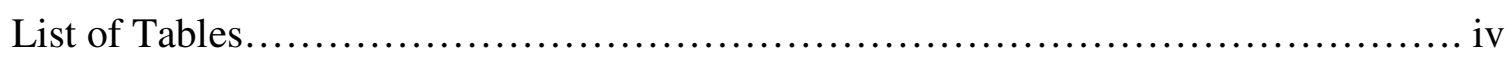

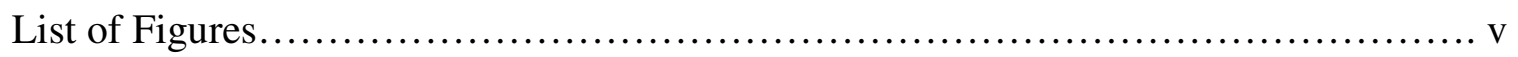

Chapter 1

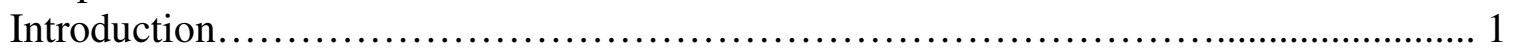

Chapter 2

Conceptual Framework....................................................... 5

Chapter 3

Literature Review........................................................ 14

Chapter 4

Research Questions, Method and Measures..................................... 35

Chapter 5

Results.................................................................... 43

Chapter 6

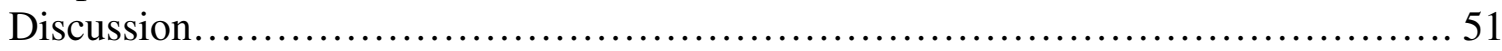

References............................................................. 75

Appendix: Measures......................................................89 


\section{List of Tables}

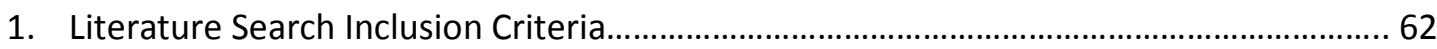

2. Examination of Dose-Response Relations in Research Studies on Workplace Stress Reduction Programs (without Mindfulness)

3. Virgili, 2013: High Quality

Studies.

4. Grossman, 2004: High Quality Studies.

64

5. Chiesa \& Serretti, 2009: High Quality

Studies.

6. Harrison Update: High Quality

Studies.

7. High Quality Studies Examining Dose/Response: Assigned and Mean

Doses.

8. MT Program Training Session Content and Length.

9. Descriptive Statistics [Means (SDs)] of All Measures for Total Sample, Treatment Group and Control

Group.

10. Research Question 1: Descriptive Statistics and Bivariate Correlations Between All Teachers' Self-Reported Meditation and Yoga Practice and Levels of Job Stress and Burnout at Baseline...

11. Standardized Betas and Bivariate Correlations for Both Groups: Research Question 2a: Differences in Generic Dose of Meditation and Yoga Frequency over Time.....

12. Research Question 2b: Bivariate Correlations Between All Teachers' Self-Reported PostProgram and Follow-Up Meditation and Yoga Practice, Levels of Job Stress and Burnout and Condition

13. Standardized Betas and Bivariate Correlations for Treatment Group Only: Research Questions 3a and 3b: Total in-Class Program Attendance Minutes and Total Home Practice Minutes Predicting Post-Program and Follow-Up Occupational Stress and Burnout. 


\section{List of Figures}

1. Frequency of Generic Dose of Meditation Practice over Time by Group....... 71

2. Frequency of Generic Dose of Yoga Practice over Time by Group.............. 71

3. Histogram of Individual Differences in Program-Specific Dose, Measured in Minutes of Mindfulness Program Attendance Among Teachers Randomized to

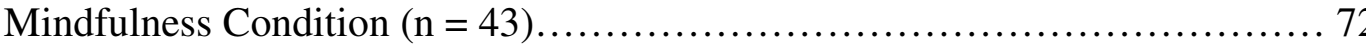

4. Histogram of Individual Differences in Program-Specific Dose, Measured in Minutes of Home Practice Among Teachers Randomized to Mindfulness

Condition $(n=43)$.

5. Test for Mediation of Intervention Condition on Teachers' Occupational Stress at Follow-Up (T3) by Teachers' Meditation Frequency at Post-Program (T2)....... 73

6. Test for Mediation of Intervention Condition on Teachers' Occupational Stress at Follow-Up (T3) by Teachers' Yoga Frequency at Post-Program (T2).......... 73

7. Test for Mediation of Intervention Condition on Teachers' Occupational Stress at Follow-Up (T3), controlling for baseline occupational stress by Teachers' Meditation Frequency at Post-Program (T2)... 


\section{Chapter 1. Introduction}

\section{Problem Statement}

Research suggests that teaching, like other human service professions, is rather stressful (Chaplain, 2008; Farber, 1999; Johnson et al., 2005). Many teachers report experiencing job stress, self-doubt, and disenchantment during their teaching careers (Kyriacou, 2001). Some research estimates that at least 30\% of teachers exhibit some symptoms of burnout (Farber, 1991; Rudow, 1999). Additionally, the rate of teachers who routinely thing about leaving the profession has been estimated to be as high as $57 \%$ (Lumsden, 1998), Teachers do in fact leave the profession at a rate of $17 \%$ per year (NCTAF, 2007), with desistance rates especially high among early career teachers (Ingersoll, 2001; Jalongo \& Heider, 2006). In one study, 32\% of teachers decided to leave the profession within the first three years of teaching (Strunk and Robinson, 2006). Though not the only reason, teachers' cite work-related stress and burnout as among the reasons they have for leaving the profession (Montgomery \& Rupp, 2005).

Research shows that teachers' job-related stress is associated with a variety of health, mental health and career-related difficulties, including stress-related illnesses, poor sleep and diet, anxiety, depression and job-related outcomes like decreased job satisfaction and increased absenteeism and turnover intentions (Guglielmi \& Tatrow, 1998, Jennings \& Greenberg, 2009; Karasek, 1979; Montgomery \& Rupp, 2005). Thus, the experience of workplace stress and related negative health, and career outcomes among teachers is clearly an important issue in the teaching profession and for 
educational leaders. New strategies for reducing teacher stress through workplace modifications, and through professional development opportunities to develop stressmanagement skills are needed in education today (Jennings \& Greenberg, 2009; Roeser, Skinner, Beers \& Jennings, 2012).

\section{Study Purpose}

In this study, I examine how the amount of time teachers spend engaging in contemplative practices like meditation and whole-body movement practices like yoga is associated with teachers' workplace stress and burnout symptoms within and across time. Preliminary evidence suggests that engagement in contemplative practices can assist teachers to learn how to regulate emotion and manage stress more effectively (Kemeny et al, 2012; Roeser et al, 2013, Winzelburg \& Luskin, 1999, etc.). To date, however, little research has been done on the question of how frequently or how much time teachers need to invest in learning and practicing meditation or yoga (i.e., "dose") to see stress reduction effects (i.e., "response"). The purpose of this study was to examine doseresponse relationships between teachers' amount and frequency of engagement in both generic, free time, mindfulness and yoga practices, as well as mindfulness trainingspecific practice, and their levels of occupational stress and burnout. How much mindfulness and yoga practice is needed before teachers' report feeling less stressed and burned out? Is there a clear threshold of time spent practicing that is needed before teachers are likely to realize change in their feelings of stress and emotional exhaustion? 
This study took place in the context of a randomized-control trial of a mindfulness-based stress reduction program for teachers that examined the effects of randomization to a treatment (mindfulness training - MT group) or a waitlist control (WC) condition on change in teachers' occupational stress and burnout from baseline (T1), to post-intervention (T2), to 4-month follow-up (T3) at the beginning of the next school year after the summer (see Roeser et al., 2013). This initial report showed that teachers in the MT condition showed lower levels of occupational stress and burnout. Additional acceptability and feasibility analyses showed participants found both in class and home components of the program to be beneficial, aligned with their goals, and overall useful.

As a follow-up to that study, this thesis examines questions associated with both generic and mindfulness program-specific dose-response relations between engagement in contemplative practices and stress and burnout in teachers. With regard to generic dose, I examine group differences in teachers' frequency of practicing meditation or movement practices generally as a function of participating in the intervention or not (e.g., treatment vs. control at T1, T2, T3); and whether or not group differences in frequency of engagement in such generic practices at T2 mediate the effects of the mindfulness training on follow-up (T3) reductions in stress and burnout.

With regard to program-specific dose, I examine whether or not individual differences in the total minutes of in-class and home practice exercises completed among teachers randomized to the mindfulness training predicted reductions in stress and 
burnout over time (controlling for baseline measures); as well as whether or not thresholds exist in program-specific dose in terms of a number of minutes after which teachers' report of stress or burnout dropped in a discontinuous way. Thus, the study aims to document if increases in engagement in contemplative practices generically, and number of minutes engaging in mindfulness training specifically, mediated the stress and burnout reduction effects of this program documented previously (Roeser et al., 2013).

\section{Organization of the Thesis}

This thesis is organized as follows: the next sections include (a) a conceptual framework in which I define teacher stress and burnout from the social-cognitive perspective on stress and coping used in this thesis, and define mindfulness and mindfulness training as a unique approach to stress management for teachers; (b) a literature review on mindfulness-based stress reduction programs, their efficacy in various populations (including teachers) and settings (including the workplace), and data previously found on generic and program-specific dose-response relations between practice and stress reduction; and (c) a set of research questions derived from the literature review that seek to clarify the nature of dose-response relations in teacher MT programs; (d) a methods section that includes a description of the sample, measures and data analysis plans used to answer my research questions; (e) a results section where I present findings for each research question; (f) a discussion of the study findings (vis à vis the research questions), strengths and limitations; and finally (g) a section on future directions for research. 


\section{Chapter 2. Conceptual Framework}

\section{Theory of Stress and Coping}

There are a variety of theories that can be used to understand the relationship between job stress, personal coping, and health and well-being, including theories of cumulative stress load (e.g., Thoits, 2010), the job demand-control theory of stress (Karasek, 1979), the person-environment fit theory of stress (Caplan, et al, 1975), and social-cognitive, transactional theories of stress (Lazarus \& Folkman, 1984; Lazarus, 2006). In this study, I draw on Lazarus and Folkman's social-cognitive theory of stress to frame this study of dose-response relations in the context of a mindfulness-based stress reduction program for teachers. Specifically, this theory frames how to think about how an increase in personal resources through a particular amount of mindfulness training (dose) might produce reductions in teachers' job-related stress and burnout (response). Lazarus and Folkman's (1984) theory of stress and coping is two-fold in nature. First, in the presence of a stressor or challenge, a primary cognitive appraisal occurs. This primary appraisal is an evaluation, rightly or wrongly by the person, that something in the perceived situation is "self-relevant" to one's welfare. Following the appraisal of a selfrelevant challenge or opportunity, this theory posits that various self-regulatory (coping) strategies/resources are activated to either prevent harm or promote well-being. Coping refers to one's effort to manage an appraisal of a challenge or a demand that is selfrelevant. According to Folkman and Lazarus (1984), stress is the result of a perceived imbalance between demands and personal/social resources needed to cope with demands. 
This theory has applications in education and is key to understanding how teachers' appraisals and coping resources are key factors in their levels of job stress and burnout (Montgomery \& Rupp, 2005). In this study, I explore the question of how much mindfulness training (dose) is needed to build resources in teachers and thereby, reduce job stress and burnout. Is there any evidence of a threshold with regard to amount of mindfulness training and its documented stress reduction effects (see below)? In the next section, I define teacher stress in terms of this theory.

\section{Application of Social-Cognitive Theory to Workplace Stress and Stress Reduction}

\section{Efforts}

Defining stress. Based on Lazarus \& Folkman's (1986) social-cognitive theory of stress applied to teachers in the workplace, I posit that teachers' job-related stress has both environmental (in terms of the demands present) and psychological (in terms of teachers' personal appraisals, resources, and efficacy beliefs regarding their ability to cope with demands) causes. Teachers' occupational stress and burnout can be conceptualized here as the result of job demands that have overwhelmed the coping and social resources teachers have at their disposal to address such demands effectively (Folkman \& Lazarus, 1986; Montgomery \& Rupp, 2005). Skinner and colleagues (2003) have documented 13 different kinds of coping resources that are relevant to teachers' ability to manage stress (see Taylor, Harrison \& Roeser, 2012); and helping teachers develop healthy appraisal styles and coping resources through mindfulness training is at the core of the intervention study examined in this thesis. 
At the same time, it is important to note that the real workplace environmental demands on teachers are considerable today. Occupational demands on teachers today include often-changing standardized testing requirements, increased class sizes, and students with increasing and increasingly varied special needs (Ingersoll, 2001). All the while, teachers are asked to meet these rising demands while at the same time being held increasingly accountable for student academic performance (Lambert and McCarthy, 2006). This increase in demands is often coupled with decreasing resources to meet those demands, in the form of reduced budgets (which in turn increase the amount and variety of jobs asked of teachers). Additionally, recent and continuing school reform efforts have done little to take into account teachers' perspectives and needs. This can leave them feeling undervalued and overworked (Farber \& Ascher, 1991; Smylie, 2005).

The daily demands of teaching also require great day-to-day resilience and flexibility. Roeser, Skinner, Beers \& Jennings (2012) characterize teaching as, "uncertain, emotional, and attentionally demanding work" (pg. 2). Teachers spend their days interacting with students, other teachers, parents, and administrators. They are required to regulate their emotions in the moment, regardless of the situation, and are rarely able to leave the classroom to do so. The authors argue that these demand characteristics of teaching can be reduced by the training of "habits of mind" (pg. 2) such as emotion regulation and mental flexibility. Given that occupational demands are high, one reason many teachers not have sufficient resources to cope with such demands is that they are not taught stress-management skills in teacher education or teacher professional development programs (Jennings \& Greenberg, 2009). 
Given that many of the stressful aspects of teaching are inherent to the nature of the profession as outlined above, one important avenue for supporting teachers, in addition to systemic reforms that aim to reduce demands or increase supports, is to offer them professional developmental programs that aim to help them in building coping resources at the individual level. Providing teachers with new resources to meet demands (e.g., mindful emotion regulation strategies, non-reactivity) and new ways of appraising self, others and the world (e.g., with love and kindness rather than fear and criticism), can support them in their efforts to cope more effectively with both transient and inherent job stressors. In this study, I examine how the amount of mindfulness training is related to reduced stress, and by implication, increased teacher personal resources. In the next section, I review the evidence for the efficacy of workplace stress reduction programs, and evidence regarding dose-response relations in such programs.

\section{Research Review of Workplace Stress Reduction Programs}

What is the evidence for the efficacy of efforts to reduce workplace stress by increasing employees' personal resources? Richardson and Rothstein (2008) conducted a meta-analysis of the effects of occupational stress management interventions on workplace stress reduction. They found an overall weighted effect size of $d=.53$ for these programs - suggesting that participation in an occupational stress management intervention predicted a reduction in stress in the training groups, as compared to the control groups, of about half a standard deviation. This is a medium effect size (Cohen, 1988). Analyses comparing different kinds of Stress Management Intervention (SMI) interventions (organizational, multimodal vs. cognitive-behavioral, relaxation, 
alternative) showed that cognitive-behavioral interventions had the largest effects. This suggests that programs to cultivate employee resources are efficacious for reducing job stress. In this meta-analysis, length of stress-management intervention did not appear to be a significant moderator of effect size, and of the 38 studies reviewed, only one examined dose/response relationships. In sum, results from this meta-analysis suggest that cognitive-behavioral stress management interventions, those that focus on training and skill-building, consistently produced larger effect sizes than other kinds of interventions. Thus, we see that skill-building is an important way to approach stress reduction in the workplace. The studies in this meta-analysis did not shed light on how much time is needed to build stress-management skills in employees. A closely related approach to the cognitive-behavioral approaches to stress-management that were found to be most efficacious in this meta-analysis are mindfulness-based stress reduction programs. In the next section, I review evidence on these programs in relation to stress reduction, as well as dose-response relations in these program effects.

\section{Mindfulness and Theory of Mindfulness-based Stress Reduction}

Mindfulness can be defined as a state, a trait or a practice. As a state, it refers to present-centered awareness in which one is focused, calm, and open and accepting towards whatever is occurring moment to moment (e.g. Kabat-Zinn, 1990). Over time, with practice, mindfulness as a state can become a trait, and individual differences in mindfulness have also been noted (see Jennings, Lantieri \& Roeser, 2012).

\section{Mindfulness Training: Mechanisms and Theory of Change}

The development of mindfulness through training is linked to increased awareness 
of mental and physical processes (sensations, emotion, auditory and visual thought, attention); as well as the ability to regulate them (Kabat-Zinn, 1990). The increased awareness of mental factors that comes with mindfulness, and related regulatory control over such "objects of awareness," is known to aid individuals in responding, rather than reacting, to emotionally-evocative life situations, and thereby decreasing physiological and psychology stress and burnout (Bishop et al, 2004). Researchers have begun to talk about "mindful emotion regulation" to understand how the application of mindfulness to issues of stress can result stress reduction, diminished emotional distress, and increased well-being (Chambers, Gullone \& Allen, 2009).

The above approaches notwithstanding, mindfulness and mindful movement training, as a novel form of stress management and resilience enhancement, may provide a unique and needed form of professional development for teachers which reduces stress and burnout (Berger \& Owen, 1988; Jennings \& Greenberg, 2009; Roeser, Skinner, Beers \& Jennings, 2012). Specifically, it's posited that mindfulness and mindful movement training foster the development of personal skills and mind-sets that can improve teachers' ability to cope in the inherently stressful world of teaching.

Mindfulness can be defined as, "a state of present-centered awareness in which one is focused, alert, flexible, calm, and compassionate toward others" (Kabat-Zinn, 1990). Mindfulness-based stress reduction (MBSR) is a structured program that uses mindfulness-based techniques, including mindful movement, the body scan, and sitting meditation, to address a variety of issues, including the improvement of occupational health. MBSR-based programs have grown exponentially in number and scope in the last 
ten to fifteen years (Cullen, 2011), but many questions remaining regarding the relationship of MBSR program elements to outcomes.

\section{Amount/Quality of Mindfulness Training: Theory of Change}

This study aims to address one of these questions; namely, the relationship of MT dose to outcomes. The concept of "dose" is one way in which intervention fidelity is calculated (Hulleman and Cordray, 2010). Additional components of intervention fidelity include quality and exposure. A full analysis of intervention fidelity measures the extent to which the program implementation that actually occurred matches the "gold standard" of the program implementation. In this study, we focus solely on an analysis of program dose and its relationship to outcomes. We define dose as quantity of time, and examine both generic and program-specific dose of MT (Follett \& Armstrong, 2004).

When considering generic dose specifically, we define this as at home, informal, unstructured engagement in any one of a variety of meditation and movement-based practices. This dose can be considered a marker of engagement with, or "buy in" to these kinds of practices. Though this dose is not structured or scaffolded by a mindfulness program instructor, higher doses are indicative of higher intrinsic motivation on the part of participants to engage in these activities, as well as higher value placed, and benefit expected, from them. Therefore, we posit that higher doses of generic practice will be related to reduced stress and burnout.

When considering program-specific dose, the theory is one of increased exposure time leading to increased opportunities to learn. In order to learn a concept, one must first "show up", so to speak. Additional presence with a mindfulness instructor will result in 
additional opportunities to learn and benefit from MT, just as additional engagement with formal home practices will. Ericsson and Charness (1994) describe the development of expertise, and examine the differences in those who perform as experts in various fields. A key component, they find, is, "extended deliberate practice" (pg. 725) that leads to the development of expertise over time. The authors state that one component in the acquisition of expertise is a surface measure of amount of time, and another is what is done with that time. That is, practice day after day that is structured, and deliberately focused on key components of the skill (rather than a more broad conception of time spent doing activities related to the skill) results in the acquisition of skills that lead to expertise. Time is required to absorb new information, to grapple with concepts that are not understood at first, and to integrate to come to a more sophisticated understanding (Bransford, Brown and Cocking, 2000). Thus, in this study we conceptualize mindfulness as a "three-fold attentional skillset" consisting of focused attention, mental clarity, and emotion regulation (Shinzen Young, 2011) that, like any complex skill, can be learned and trained through sustained and socially-scaffolded practice over time (Ericsson \& Charness, 1994).

Additionally, we focus on both generic and program-specific practice, with a view of these two quantities of dose as markers of motivation to engage in the practice. That is, generic dose, undertaken of one's own volition, is an indicator of engagement with a practice. Likewise, program-specific dose, defined as attendance and completion of assigned home practice, are an indicator of engagement with MT.

In this study, we explore the relationship between the amount of both generic and 
program-specific practice of mindfulness meditation and mindful movement/yoga and the outcomes of occupational stress and burnout. 


\section{Chapter 3. Literature Review}

In this section, I begin with an example of several approaches to stress reduction in schools. I then review evidence for the efficacy of mindfulness training and stress/distress reduction and mood improvement in clinical and community-based samples of adults. An initial literature search revealed three meta-analyses on the effect of mindfulness-based programs on mental health outcomes. I also conducted a search to update/supplement the literature, findings of which will be discussed. In the high quality studies (i.e., randomized, controlled trials) where efficacy was demonstrated, I review those which examined dose/response relations between amount (dose) of MT and stress/distress reduction and mood improvement (response) effects.

The definition of dose as used in this study is minutes of exposure to mindfulness training. This includes minutes of program-specific dose, including in class contact (defined as number of program sessions attended, multiplied by the length of the sessions) and minutes of total self-reported home practice of program-specific, guided meditations, and minutes of generic dose, defined as minutes of meditation and yoga practice engaged in that is not a part of the MT program. When I review studies which use alternate definitions of dose, the definition will be given. Outcomes of interest were restricted to stress/distress (self-report as well as physiological), burnout, depression and anxiety, and overall mood for the purposes of this literature review.

\section{Current (Non-Mindfulness) Approaches to Stress Reduction in Schools}

Intervention strategies targeting occupational stress and burnout are diverse; 
including both preventative and intervention programs for teachers experiencing burnout (Maslach, Schaufeli, Leiter, 2001).

Cecil and Forman (1990) assessed the effect of stress inoculation training and coworker support on fifty-four regular classroom teachers. The stress inoculation training, which took place in nine hours over six weeks, and covered relaxation training and practice using coping skills, was found to reduce teachers' stress and enhance their coping skills, compared to the support group condition, which also took place over six weeks, and in which teachers could share problem solving strategies and give each other instructional, social and emotional support.

Cheek, Bradley, Parr and Lan (2003) assessed the impact of either a cognitive behavioral or a combination cognitive behavioral/music therapy on fifty-one elementary school teachers. Each program took place in seven and a half hours over six weeks, and the music therapy group played music, and discussed processed it in terms of its ability to reduce stress. Results showed greater reductions in burnout for the music therapy group, specifically relating to depersonalization and personal accomplishment.

\section{Workplace Stress Reduction: Mindfulness Programs}

Virgili (2013), conducted a meta-analysis examining the effectiveness of Mindfulness-Based Interventions (MBIs) for the reduction of psychological stress/distress in working adults specifically. See Tables 1 and 2 for details. The literature search resulted in 19 studies meeting all inclusion criteria. 
Within-group effect sizes were calculated for each group as the difference between post and pre-program scores over the pooled standard deviation. Hedges's $\mathrm{G}$ is reported to correct for the potential bias of small sample sizes.

Results of the meta-analysis showed an overall within-group, pre-post effect size (Hedges's g) of 0.68. Effects seemed to persist at follow-up, with an overall effect size, Hedges's $g=0.60$. Moderator analyses were conducted to examine the relationship between MT dose and outcomes. Here, dose is defined as the number of in class contact hours and the length of the program (in weeks) as described by the researchers. This is distinct from the definition of dose used in this study, in that no information is available on individual differences of dose actually received during the intervention. Firstly, studies were grouped into "brief" and "full" groups, comparing studies with fewer than 20 in-class contact hours and those with 21 or more in-class contact hours, respectively. Results showed effect sizes across the two groups were not significantly different. Additional analyses looking at in-class contact hours as a continuous variable also did not show a significant relationship between number of hours and effect size. A second approach to this question by Virgili was to group interventions according to length $(4-6$, 8 , and $10-12$ weeks). Overall results showed effect sizes were not significantly different across the three groups. Additionally, effect size was also showed to be unrelated to intervention length when length was coded as a continuous variable.

Virgili did not examine dose as defined in this study (minutes attendance, program-specific home practice, and generic practice), but one study in the meta-analysis 
did examine the dose/response relationship using this definition (see Tables 3 and 7 for details).

Davidson et al, 2003 examined the effect of an 8-week MBSR program on selfreported anxiety and positive and negative affect, as well as the underlying biological changes, specifically immune function, related to physical and mental health, in 25 subjects, as compared to 16 subjects in a waitlist control group. Results showed significantly greater reduction over time in anxiety in the treatment group as compared to the control group, no effect size given. Descriptively, participants reported practicing an average of 16 minutes per session, with an average of $2 \frac{1}{2} 2$ home practice sessions per week. Thus, average total dose of home practice was 320 minutes. Dose/response analyses showed no significant correlations between either duration or frequency of home practice and outcomes. No information was given regarding average program attendance.

\section{General Mindfulness Stress Reduction}

Grossman, Niemann, Schmidt and Walach (2004) conducted a meta-analysis investigating the relationship of Mindfulness-Based Stress Reduction (MBSR) and MBSR-based programs to mental health outcomes, including anxiety, depression, and mood. See Tables 1 and 2 for details.

Samples included those with clinical diagnoses, prison populations, and nonclinical, community samples. The literature search yielded seven high quality, randomized studies, and three that were quasi-experimental. See Table 4 for details. 
Cohen's $d$ was calculated for each group as the difference between treatment and control group measures of outcomes, divided by the pooled standard deviation. Results across the ten studies for mental health outcomes showed an average treatment vs control group effect size of Cohen's $d=.54$. Results were not significantly different when comparing studies with clinical and community samples, nor were they significant when comparing randomized and quasi-experimental studies.

Of the ten studies, two examined the relationship between MT dose and outcomes (see Table 7 for details). Sephton et al (2007) examined the effects of an 8-week MBSR intervention, as compared to a control group, on depressive symptoms in women with fibromyalgia. Results showed reduced depressive symptoms in the treatment group, as compared to the control group, $\eta^{2}=.12$. To assess dose/response relationships, the authors examined both program attendance $(\mathrm{M}=5.5$ sessions, or 13.75 hours $)$ and presence of home practice of meditation. Results showed that higher attendance rates were not significantly related to greater improvements in outcomes. Regarding presence of home practice, 35 treatment and 3 control participants reported engaging in regular meditation practice at post-program, with the median for both groups being 5 occasions per week. At follow up, 24 treatment and 3 control group participants continued with a regular meditation practice, with medians of 7 and 4 occasions, respectively. Those who still meditated at follow up reported significantly greater reductions of depressive symptoms and somatic complaints. In sum, dose defined as presence of regular 
meditation practice following training was shown be related to greater reduction of depression and somatic complaints.

Speca et al (2000) assessed the effect of an MBSR-based program on mood and stress in cancer outpatients. The program took place over 7 weekly 1.5 -hour sessions. Results showed that, compared to the waitlist control condition, treatment group participants had reduced mood disturbance, depression, stress, anxiety, anger and confusion, and more vigor. Regarding dose/response analyses, the authors found that dose, defined as the number of program sessions attended from $0-7$, (Mean for treatment completers $=6$ sessions, or 9 hours) did not significantly predict mood disturbance scores. The researchers theorized that this could have been due to the restricted range of attendance scores (details not provided). However, the authors did find a significant correlation between attendance and stress, such that greater attendance was significantly negatively correlated with stress scores. The authors also examined the relationship of dose of home practice to outcomes. Results showed that average daily meditation time was 32 minutes (or 1568 minutes total), that average minutes of meditation time significantly predicted mood disturbance and POMS (Profile of Mood States) scores, and that total minutes of meditation practice time significantly predicted mood disturbance scores.

In sum, two studies in this review examined the relationship between MT dose and response. These two studies found a mix of positive and nonsignificant relationships between measures of MT dose and response outcomes. 


\section{Community Mindfulness Stress Reduction}

In a more recent meta-analysis, Chiesa and Serretti (2009) examined the relationship of mindfulness meditation on stress reduction in community samples (see Tables 1 and 2 for details).

The literature search resulted in ten studies which met the inclusion criteria (see Table 5 for details). Results comparing MBSR to inactive treatment groups included seven studies, and found significantly larger effect sizes in MBSR groups as compared to the inactive treatment groups (Mean effect size MBSR group, $d=.74$, Mean effect size Control group, $d=.21$ ). Cohen's $d$ was calculated for each group as the difference between post and pre measures of outcomes, divided by the pooled standard deviation. The remaining three studies also found significant reductions in stress compared to the control groups, though each was excluded for various methodological limitations.

Regarding dose/response, 2 studies in the meta-analyses examined the relationship. Jain et al (2007) examine the effect of a 4-week MBSR-based program on stress in 83 students, as compared to a relaxation group and a no treatment control group. Results showed significant reductions in distress at post-program in both active groups ( $d$ $=1.36$ ), as compared to the control group, with no significant differences between the two treatment groups. Dose/response analyses found no significant difference effect of total number of hours of practice $(M=5.27)$ and Global Severity Index (GSI) scores. However, there was a marginally significant effect of hours of practice on Positive States of Mind (PSOM) scores. 
Vieten and Astin (2008) assessed the impact of an 8-week MBSR-based program on stress and anxiety in 31 women in the late stages of pregnancy. Results showed significant reduction in anxiety $(d=.85)$, compared to a waitlist control group. Analyses also showed no significant relationship between attendance ( $\mathrm{M}=7.2$ sessions, or 14.4 hours) and outcomes.

In sum, two studies in this review examined dose-response relations, and those that did, did not find significant relationships between measures of dose and response outcomes.

\section{Harrison Update Mindfulness Stress Reduction Findings}

To complete the literature review on dose/response approaches in high quality studies of MBSR programs on stress, I conducted an additional literature search (see Tables 1 and 2 for details). The search revealed eleven high quality studies which reviewed the relationship of mindfulness-based interventions and the mental health outcomes, for both clinical and community populations (see Tables 6 and 7 for details).

Biegel et al (2009) examined the effect of randomization to an 8-week MBSR program on various mental health outcomes in 102 adolescent psychiatric outpatients. Results showed that, compared to a treatment as usual (TAU) group, significant improvements in state and trait anxiety, perceived stress and depressive symptoms over time, with medium to large effect sizes. The authors examined dose/response relationships in several ways. They found that more days of sitting practice significantly 
predicted decreases in depressive and anxiety symptoms and increases in Global Assessment of Functioning (GAF) scores from baseline to follow-up. In an alternate conceptualization of dose, average length of sitting practice sessions per week was found to predict significantly greater decline in depressive and anxiety symptoms, and greater increase in GAF scores from baseline to follow-up. Descriptives around measures of dose were not provided, but the findings show support for the idea that more days, as well as greater average amount of time of practice are related to more positive outcomes.

Daubenmier et al (2012) assessed the impact of randomization to a 9-week mindfulness-based intervention for 47 overweight and obese women on stress, anxiety and telomerase length. Results showed no significant difference in the groups on stress from pre-to post-program, but did see an effect of group on anxiety. Dose response analyses included an examination of the relationship of attendance rates and outcomes. Higher attendance (no mean given) was marginally significantly related to greater increases in telomerase, but no other dose/response relationships were seen.

Geschwind et al (2012) examined the impact of an 8-week MBCT program on 130 adults with a history of depression. Results showed significantly greater reduction in depressive symptoms in the treatment group, compared to the control group. Regarding dose/response analyses, results showed that average daily minutes of mindfulness practice $(\mathrm{M}=25-28$ minutes, or $1400-1568$ total minutes) was significantly related to improvements in depressive symptoms. 
Gross et al (2010) examined the impact of an 8-week MBSR program on anxiety and depression in 138 organ transplant patients, compared to an active control (health education) group. Results showed significantly greater reductions in anxiety in the treatment group $(d=.51)$, compared to the control group. Regarding dose response analyses, the authors examined home practice levels, and found that average daily minutes of home practice $(M=29$, total home practice $M=1624)$ was positively correlated with reduced anxiety and increased mindfulness. The correlation between average daily home practice and depression was in the expected direction, and was marginally significant.

Guardino et al (2013) assessed the impact of a 6-week Mindful Awareness Practices class for 47 pregnant women on stress and anxiety reduction. Results showed a significantly larger reduction in stress and anxiety in the treatment group as compared to the control group (no effect size given). The authors found no significant correlations between either number of classes attended $(\mathrm{M}=4.75$ of 7 , or 9.5 hours $)$ or amount of home practice (no descriptives given) and outcomes.

Hoffman et al (2012) examined the effectiveness of a 6-week MBSR program on anxiety and depression in 229 women with stage 0 - III breast cancer. Results showed significantly greater reduction in anxiety and depression post-program in the treatment group compared to the control group (no effect sizes reported). Regarding dose/response analyses, the authors found that greater total hours of in-class $(\mathrm{M}=17.45)$ and program- 
specific home practice $(M=19.58)$ over the 8 weeks of the intervention significantly predicted reduced anxiety as well as overall mood improvement at follow-up.

Lengacher et al (2009) assessed the impact of a 6-week MBSR-based program on stress, anxiety and depression in 84 female breast cancer survivors, compared to a TAU group. Results showed significantly lower levels of depression and anxiety in the treatment group, post-program (no effect sizes given). The authors also examined the impact of 'compliance' (defined as $>=75 \%$ program session attendance, and completing $>=75 \%$ of the assigned home practice) on outcomes. Using this definition, $70 \%$ of the participants were classified as compliant. Results showed that being compliant did not produce mental health scores that were significantly lower than those who were noncompliant. Additionally, greater total minutes of home practice $(\mathrm{M}=1077)$ was significantly correlated with reductions in perceived stress. Surprisingly, greater home practice was also significantly negatively correlated with optimism. Number of minutes of home practice of yoga, specifically, was not significantly related to outcomes. This study thus provides some support for the idea that greater amounts of MT can lead to greater improvements in well-being.

Carson et al (2004) assessed the impact of an 8-week mindfulness-based relationship enhancement program on the moods of 88 individuals who were in a happy, non-distressed relationship. Results showed significantly greater reduction of psychological distress in the treatment group, as compared to a waitlist control group (no effect size given). Dose/response analyses included an examination of the relationship of 
daily practice (no mean given) to same day outcomes, as well as to outcomes using a lag of 1, 2 and 3 days' practice. Results showed that all same-day tests were significant and in the expected direction, including decreased overall stress and decreased relationship stress. Lagged tests showed that greater mindfulness daily practice was significantly predictive of decreased relationship stress for the following day as well as for the second day. Analyses also showed marginally significant relationship between daily mindfulness practice and stress on the third day, $p=.08)$.

De Vibe et al (2013) examined the impact of a 6-week MBSR program for 288 medical and psychology students on mental distress and well-being. Results showed significantly greater reductions in mental distress, and improvements in subjective wellbeing in the treatment group compared to the control group. Dose response analyses looked at both program attendance (with a range of $1-7$ days) and home practice levels (no descriptives given), and showed no significant relationship between dose and outcomes.

Hou et al (2013) assessed the impact of an 8-week MBSR program on the mental health of 71 family caregivers. Results showed significantly greater reduction in depression at post-program and follow-up in the treatment group, compared to the control group, as well as significantly greater anxiety reduction in the treatment group at postprogram (no effect sizes given). To analyze dose/response effects, the authors examined total number of sessions attended $(M=6.76$, or 13.5 hours $)$ as well as average minutes of 
weekly home practice $(\mathrm{M}=34.4$, or 275 total $)$. Neither of these measures of dose were associated with any outcome measures.

Nyklicek \& Kujipers (2008) examined the effect of an 8-week MBSR program on 60 participants with symptoms of distress. Results showed a significantly larger reduction in distress in the treatment group $(d=.64)$ compared to the control group. Dose/response analyses showed no significant relationship between home practice $(\mathrm{M}=4.32$ sessions per week) or attendance ( $\mathrm{M}=6.48$ sessions, or 13 hours $)$ and outcomes.

\section{Teacher/Educator Mindfulness Studies}

To review literature examining the impact of mindfulness training on teachers, a search was conducted on Google Scholar and PsycInfo for the terms, "MBSR", “mindfulness", "teachers", “instructors", "educators", in various combinations. Given that only a few studies have examined this relationship to date, inclusion criteria were changed from those outlined above to allow the addition of pre-post studies whose design did not include a control group. All other inclusion criteria remained the same. This literature search resulted in 13 studies, none of which examined the relationship between MT dose and outcomes.

Winzelberg and Luskin (1999) describe an experimental study of a meditationbased stress reduction intervention for teachers that consisted of four 45-minute training sessions over four weeks. The study, conducted with 21 students in a teacher-training 
program, found significant reductions in stress for those receiving meditation training. No relationship between dose of training and outcomes was examined.

Poulin et al (2008) in a quasi-experimental study, examined the effect of participant in an MBSR-based course or a control group on 4 teachers and teacher trainees. Participants self-selected into either a course on stress and burnout, or a variety of other elective courses. The stress and burnout course included 8 weeks of training in the Mindfulness-Based Wellness Education (MBWE) course. Number of class contact hours was not given, but the amount of home practice suggested was given as $15-20$ minutes, five days per week. Results showed that participation in the intervention was related to significant improvements in the Observe and Act with Awareness subscales of the KIMS (Baer et al, 2003), as well as improved satisfaction with life and teaching efficacy. There was no effect of group seen on psychological distress. Dose/response relationships were not examined.

Franco et al (2010), in a quasi-experimental study, assessed the impact of an MBSR-based intervention on 68 secondary school teachers. The program took place over 10 weekly 1.5 hour-sessions, and included a home practice component of 40 minutes daily. The control group took part in a psychomotor therapy program, which consisted of playing games and doing exercises with balls and music. They were also assigned home practice for 40 minutes daily; specifically, to close their eyes, and listen to relaxing music. Researchers found decreased psychological distress at post-program in the experimental group, compared with the control group, and these effects persisted at 
follow-up. Again, the dose/response relationship between MT and outcomes was not examined.

Jennings, Snowberg, Coccia and Greenberg (2011) report the effects of a mindfulness-based occupational health program for teachers that included four day-long sessions taking place over 4-5 weeks. The program, designed to reduce teachers' stress and promote well-being, efficacy and mindfulness, was assessed in two studies using samples of teachers in a lower SES urban setting, and student teachers in a suburban setting. Researchers reported mixed moderate results regarding increases in mindfulness and reductions in time urgency, and suggest further exploration into the evaluation of social and emotional competence (SEC) programs for teachers. The relationship between program dose and outcomes was not examined.

Benn, Akiva, Arel and Roeser (2012) looked at the effects of the SMART-inEducation program (which took place twice a week for 5 weeks) for teachers and parents of children with special needs. Results showed reductions in distress and increases in various measures of well-being for both parents and teachers that persisted at 3-month follow-up. No dose/response relationships were examined.

Gold et al (2010) in a pre-post study, assessed the effect of an MBSR intervention on eleven primary school teachers. Results showed some significant findings, including depression and stress reduction, from pre to post intervention, but the authors note several limitations, including small sample size and the lack of a control group. Dose/response relationships were not examined. 
Kemeny et al (2012) evaluated the effects of a mindfulness intervention on the wellbeing of teachers. Teachers took part in an 8-week, 42 hour meditation/emotion regulation training, and analyses should self-report and behavioral reduction of depression and anxiety, and increases in positive affect and recognition of emotions. No dose/response relationship were examined.

Flook et al (2013), examined the impact of an MBSR-based course modified specifically for teachers, on 18 elementary school teachers. The program included 26 class contact hours over 8 weekly sessions, and suggested home practice for $15-45$ minutes, 6 days per week. Teachers were randomized to either the intervention or waitlist control groups. Results showed a variety of effects in the expected direction, including significant reductions in burnout and increases in self-compassion in the intervention group, as compared to the control group. Results, for the most part, showed medium to large effect sizes favoring the intervention group. Again, no relationships between MT program dose and outcomes were examined.

Jennings et al (2013) examined the impact of the CARE program on 50 teachers, most at the elementary-school level, as compared to a waitlist-control condition. The program included 30 in-class contact hours, as well as a home practice component (no details were given as to the suggested amount of time). Compared to the control group, intervention group participants were found to have significantly increased well-being and efficacy, and significantly reduced stress and burnout. No dose/response relationships were examined. 
Roeser et al (2013) conducted a randomized, waitlist control study on the effects of the SMART-in-Education program (36 hours over 11 weeks) on 113 elementary and secondary school teachers. The intervention group showed improvements in mindfulness, focused attention working memory capacity and occupational compassion, and reductions in occupational stress and burnout at post-program and follow-up. No dose/response relationships were examined.

Frank et al (2013), in a quasi-experimental study, assessed the impact of an MBSR-based program as compared to a waitlist control group. The sample included 36 high school educators, randomized to either group. The intervention included 8 weekly 2hour sessions, and recommended home practice of 25 - 30 minutes daily. Results showed improved self-regulation, self-compassion, mindfulness and sleep quality in the intervention group, compared to the control group. Again, no dose/response relationships were examined.

Studies of MBSR for teachers have featured interventions with a range of 3-42 class contact hours (of those whose length were given in the article). Total suggested home practice amounts (calculated by multiplying the recommended daily or weekly practice amount by the length of the intervention) ranged (for studies which provided enough information to make this variable calculable) from 13 to 47 hours. Total possible program-specific dose (the combination of in-class and at-home practice) could be determined for four of the studies, and ranged from $44-62$ hours. In sum, no studies of mindfulness-based interventions for teachers have examined dose/response relationships. 


\section{MBIs for Stress Reduction: The Role of Home Practice}

Vettese et al (2009) provide a review of the research published through 2009 on the relationship between home practice of mindfulness-based interventions and outcomes. The authors searched for the terms, "mindfulness-based stress reduction", "MBSR", "meditation-based stress reduction program", "mindfulness-based cognitive therapy", "MBCT", "mindfulness group", "mindfulness homework", and, "mindfulness practice". Inclusion criteria were, (1) mindfulness meditation was the central component of the treatment program, (2) when practice data was reported, it was analyzed in relationship to outcomes, (3) study design included case studies, effectiveness studies, and clinical trials. Twenty-four studies were found to meet the criteria and to examine the relationship between home practice and outcomes. The authors report high variance in the measures

of dose reported, including measures of compliance (percentage of participants reporting a set percentage of the suggested homework), post-program compliance, daily minutes of practice, total hours of practice over the length of the program, and post-program practice. Of the 24 studies, 11 reported mean minutes of daily practice (M across studies =31.8). Three studies reported mean total hours of practice over the length of the program $(5.3,15.8,30.3)$.

Regarding dose/response analyses, eight of the identified studies found relationships between home practice and outcomes in the expected direction, five reported a mix of positive and nonsignificant findings, eight found no significant relationships, and two found relationships between dose and outcome that were opposite 
of the expected direction. An examination of the studies revealed that those with aimed at stress reduction and samples of participants in the health field were more likely to have dose/response relationships in the expected direction.

\section{Literature Review Summary}

In sum, a review of the literature reveals a lack of clear relation between MT dose and outcomes, including stress/distress and mood. To date, sixteen studies have examined this relationship, using a variety of definitions of dose (see Table 7 for details). Five studies found a relationship between dose and response in the expected direction. Four studies found a mix of relationships in the expected direction, relationships in the unexpected direction, and null findings. Seven found no significant relationship between MT dose and response.

Of the studies reviewed, multiple different definitions of dose were used when examining its relationship to outcomes. Six studies focused solely on average number of minutes or hours of daily or weekly home practice; six studies focused on definitions of dose similar to or matching that used in this study (total number of minutes of programspecific home practice and class attendance). Several studies focused on the number of practice occasions, and several used one or more of these definitions of dose. Thus, we see that multiple different definitions of dose have been used to operationalize this concept.

Additionally, when we distinguish between assigned (total possible) dose and self-reported (actual) dose, we see a wide range of "possible doses". Assigned dose was calculated whenever enough information was given in the article, by summing the 
number of hours of the MT program, and the total number of minutes of suggested home practice (for example, 45 minutes per day, 6 days per week, over 8 weeks, would be 2160 minutes). Of the studies that examined dose, assigned program doses were found to range from $360-4560$ minutes, or $6-76$ hours.

We also see a wide range of self-reported actual dose (minutes of self-reported attendance and home practice), which were calculated when enough information was given. Mean self-reported dose ranges from $316-2222$ minutes, or 5 1/4 - 37 hours. An examination of the findings in relationship to either the assigned or self-reported program dose does not point to a clear pattern of relationships. Thus, on the whole, the relationship of MT dose to outcomes remains unclear.

Additionally, no studies to date have examined dose-response relations in teachers. Given that teachers are generally those for whom time is at a premium, and as mindfulness-based teacher PD programs become more prevalent, it is important to increase understanding of this relationship. It's possible that feasible, shorter amounts training are adequate for teachers to see substantial benefits to their occupational health. Alternately, it's possible that training under a certain number of hours is not effective or long-lasting. Either finding would be important in guiding the decisions of school districts with tight budgets who are charged with providing high quality, feasible professional development to their teachers who lead busy lives. This study is an attempt to address this gap in the research on the relationship between MT dose and response in teachers. 
Using number of minutes of self-reported practice at home and in-class as a metric, this study examines the relationship between individual differences in the total program-specific MT received (both in class, as well as during practice of assigned home practice) and outcomes of stress and burnout. The next section outlines the specific research questions of this study. 


\section{Chapter 4. Research Questions, Method and Measures}

\section{Research Questions}

\section{Research Question 1: Generic Dose-Response Among All Teachers: Relationship to Stress and Burnout}

Generally, among all teachers in the study at baseline (T1), does the frequency of teachers' practice of meditation or yoga relate to baseline levels of job stress or burnout among teachers in both the control and treatment groups $(\mathrm{n}=113)$ ?

\section{Research Question 2: Effects of Group Randomization on Generic Dose-Response Among All Teachers and Dose Mediation of Group/Stress and Burnout Relationship}

A. Does frequency of generic mindful meditation and yoga go up over time (from baseline (T1) to post-program (T2) to follow-up (T3)) in the treatment group, as compared to the control group $(\mathrm{n}=113)$ ?

B. Is the relationship between group (T1) and stress and burnout at follow-up (T3) mediated by post-program frequency of generic mindfulness meditation and yoga practice $(\mathrm{T} 2)(\mathrm{n}=113)$ ?

\section{Research Question 3: Specific Dose-Response Effects on Stress and Burnout Among Teachers in Treatment Condition Only}

The third research question examines specific-dose response relations with regard to the mindfulness training and teachers randomized to this training in the original study (Roeser et al., 2013). Question 3a asks: Does the total number of minutes of mindfulness 
program attendance and program-specific home mindfulness practice that teachers report during a 9-week mindfulness training program relate to the amount of benefit they receive from the program in terms of reductions in occupational stress and burnout at the end of the program and 4 months later at the beginning of a new school year? Question 3b asks: Is there a threshold at which the relationship between program dose and stress and burnout changes significantly among teachers randomized to the mindfulness training $(\mathrm{n}=58) ?$

\section{Method}

\section{Sample}

The study sample was recruited from two suburban school districts; one in the Western United States and one in Western Canada. Researchers conducted two randomized, waitlist-control trials (RCTs), targeting 30 participants per condition (treatment, waitlist control) per research site, or 60 participants per study sample. Recruitment took place via flyers sent to each teacher in each of the two school districts. The first 65 teachers to respond to the flyers were considered for the program. Participation in the program was free, and participants were compensated with gift certificates for their completion of assessments at each time point.

The Canadian sample that completed pre-tests measures at baseline included 58 teachers (52 women, 6 men, 50\% elementary level), who were 67\% European-Canadian, 18\% Asian-Canadian, and 15\% other races/ethnicities (French-Canadian, Aboriginal, Filipino, US Black Canadian). All teachers reported having at least a bachelor's degree, 
with $22 \%$ reporting additional post-bachelor's education, and $35 \%$ reporting having master's degrees.

The US sample that completed pre-tests measures at baseline included 55 teachers (48 females, 7 males, 51\% elementary level) who identified as 93\% European American, 5\% mixed ethnicities, and 2\% Asian American. All teachers reported having their bachelor's degree, with $73 \%$ reporting having a master's degree and $7 \%$ reporting having a JD or $\mathrm{PhD}$.

The Canadian and US groups were compared on baseline and demographic measures, to assess group equivalence. Chi-square statistics showed the two groups to be equivalent with regard to sex and school level. ANOVAs were conducted to compare group differences across study site and condition with regard to teachers' age and years of experience. Results showed the Canadian teachers $(\mathrm{M}=44.63$ years $)$ to be significantly younger than the American teachers ( $M=48.95$ years). However, following randomization, there were no differences in age by condition across the samples. No differences were found across samples with regard to teachers' years of experience.

Additionally, group equivalence after randomization on outcome measures was assessed. No main effect of condition or site, or their interaction, was found for baseline measures of occupational stress. However, control group participants in both samples reported higher levels of occupational burnout than experimental group participants. We account for these differences by using baseline measures (T1) of stress and burnout as controls in all analyses where we can, and where we cannot (e.g., meditational analyses), 
we note that these initial group differences work against us finding statistically significant effects on burnout and the mediation of these effects by group.

\section{Descriptives}

Given the general equivalence of the groups, the two groups were combined into a single study sample. The combined sample thus includes 113 teachers, $88 \%$ female, with ages ranging from 27 to $64(\mathrm{M}=46.5, \mathrm{SD}=9.5)$, and years of teaching experience ranging from 1 to $35(\mathrm{M}=14.9, \mathrm{SD}=8.5$, Median =13, Mode =6).

\section{Design}

Upon enrollment in the program, participants were randomly assigned to either the 35-hr treatment group or the waitlist-control group. Self-report measures were collected at three times: baseline (T1, February - March), post-program (T2, June), and at a 4-month follow up (T3, October of the following school year). Participants assigned to the MT condition in Canada and the USA completed the training in the spring of 2009 or 2010, and those in the waitlist-control condition completed the training during the fall immediately following T3 data collection (October - December, 2009 or 2010), respectively.

\section{Intervention}

The MT program was developed as a means of cultivating teachers' habits of mind, such as focused attention, mindful awareness, emotion regulation and empathy. Sixty percent of the program is made up of a traditional Mindfulness-based stress reduction (MBSR) developed by Jon Kabat-Zinn (1990), 30\% focused on the application of mindfulness to core social and emotional issues in teaching, and the remaining $10 \%$ 
focused on teachings of kindness, compassion and forgiveness. The latter includes practices such as working with anger, fear and forgiveness; as well as practicing selfcompassion and compassion for others. These types of emotions likely to be especially prevalent in a highly stressful field such as teaching where interpersonal relationships permeate the work.

The MT program took place over eleven sessions, including one $1 \frac{1}{2}$ hour session, eight $2 \frac{1}{2}$ hour sessions, and two all day (6 hour) retreats, for a total of $33 \frac{1}{2}$ hours. Each group session included didactic and group discussion activities, question and answer sessions, modeling of mindful behavior, as well as periods of guided mindfulness meditation and/or mindful movement. Mindfulness practices included focused attention meditation on the breath, or on compassion toward others and oneself. See Table 8, below, for information on the general content and the length of each session. Participants also completed weekly homework assignments, including assignments around specific topics as well as journals of home meditation frequency and duration. Suggested frequency of meditation practices was 15 minutes per day, six days per week, for a total possible suggested home practice dose of 720 minutes, or 12 hours. Thus, for this program, there was a total possible assigned dose of $45 \frac{1}{2} 2$ hours.

\section{Measures}

Surveys were administered at baselines, post-program and 4-month follow-up. These- surveys assessed teachers' demographic backgrounds, mindfulness, and levels of occupational stress and burnout, among other variables. An appendix continuing the 
measures used in this study, as well as the means, standard deviations and alphas for each of the scales, is presented in Table 9.

Generic and Program-Specific Measures of Dose. Teachers' amount of mindfulness practice was measured in two ways. First, we measured "generic dose of practice" in terms of teachers' self-reported frequency of meditation and yoga. These were "lifestyle" questions and were distinct from meditation or movement practices assigned as part of the MT program specifically. Participants were asked whether they had a mindfulness or yoga practice, and if so, how often they practiced, and for how long they had been practicing. The question, "How often do you practice your meditation/yoga practice now?" was rated on a Likert-style scale from 1 - 8, with 1 being, "Never/Less than once a year" and 8 being, "Several times a day". This was the measure of generic dose used across all teachers $(n=113)$ in this study. Variation in these measures of generic dose across teachers randomized to the two groups at baseline, post-program, and follow-up are presented in Figures 1 and 2 and Table 9.

Two additional measures of "program-specific dose of practice" were also used with regard to those randomized to the mindfulness training conditions $(n=58)$. First, we created a measure of teachers' in class mindfulness practice based on teachers' selfreported and instructor-reported program attendance. These two measures were nearly identical and so the instructor report was used in this study. The mindfulness instructor marked individuals' attendance session by session. This allowed us to calculate the specific number of minutes of total program attendance (given that the sessions were of different time lengths). Total number of hours/minutes of attendance at group 
mindfulness sessions was calculated for each teacher in the MT based on the length of time of the sessions each individual teacher attended.

A second measure of "program-specific dose of practice" for those in the mindfulness conditions consisted of the number of hours/minutes of home practice that teachers' self-reported doing on a daily basis. Teachers were asked to keep a daily diary of their practice during the entire course of the mindfulness training program. Participants logged the number of minutes of practice and the kind of practice undertaken each day for the duration of the program. These diaries were collected and coded at the completion of the program. For each teacher, we derived a measure of self-reported number of minutes of home mindfulness practice as the sum of reported home practice hours/minutes across the entire 9 weeks of the program. Variation in these measures of specific dose across the teachers are presented in Figures 3 and 4 and Table 9. Descriptively, participants attended the training for an average of 31 of the 33.5 possible hours of the training $(\mathrm{SD}=2.66)$, and participated in an average of 13.8 hours of homework ( $\mathrm{SD}=9.7$ ) of the 16 recommended (see Figures 3 and 4). Thus, we see that most participants attended almost all program sessions and participated in more than twothirds of the recommended daily practice.

Job stress. Teachers' job stress was assessed with seven items taken from a longer inventory of teacher stress from Lambert \& McCarty (2006) and two items assessing feelings of being overwhelmed by students' socio-emotional and academic needs (Roeser \& Midgley, 1997). Participants rated on a scale of 1 to 5 how much they 
agreed with statements like, "I find trying to be attentive to the needs of fellow teachers is very stressful" and "Having to participate in school activities outside of normal working hours is stressful for me." Occupational stress was computed as the mean of these nine items; alphas were conducted at each site at each time point (see Table 9, Cronbach's alphas across three time points $>.60$ ).

Occupational burnout. Burnout was measured using the Maslach Burnout Inventory (Maslach et al, 1981), a 22-item scale with three subscales: emotional exhaustion, depersonalization, and personal accomplishment. Participants rated on a scale of 1 to 7 (with 1 = never, 7 = everyday) how often they experienced symptoms on these three domains. Example items include "I feel emotionally drained from my work" and "I feel used up at the end of the work day". Burnout was computed as the mean reported frequency of the 22 items. Cronbach's alphas conducted for each site at each time point for the full scales were reliable (see Table 9, Cronbach's alphas across three time points > $.80)$.

Additionally, most analyses controlled for teachers' years of experience, measured by self-report at baseline. Years of teaching experience was covaried out in all analyses due to the possibility of its impact on teacher stress and burnout, with younger teachers generally showing higher stress (see Klassen \& Chiu, 2010). We wanted to examine the effects of dose controlling for this source of variance in our outcome stress. 


\section{Chapter 5. Results}

\section{Research Question 1: Generic Dose-Response: Relationship to Stress and Burnout}

Research Question 1 sought to explore whether teachers' self-reported frequency of meditation and yoga practice (i.e., generic dose) at baseline (T1) was associated with their levels of stress and burnout. RQ 1 thus examines the relationship in both treatment and control teachers between this measure of generic dose and stress and burnout at baseline, using correlational analyses.

Descriptive results, presented in Table 10, showed that, on average, all teachers reported meditating less than once per year $(\mathrm{M}=1.97, \mathrm{SD}=1.60) ; 1=$ "Never", $2=$ “About once or twice a year") and doing yoga about once a year ( $\mathrm{M}=2.27, \mathrm{SD}=1.60 ; 2$ = "About once or twice a year", 3 = "About once a month"). Bivariate correlations, presented in Table 10, showed no relation between the teachers' (relatively infrequent) generic practice of meditation and yoga and their levels of occupational stress and burnout at baseline.

Additional analyses examined the correlation between the Emotional Exhaustion subscale of the Maslach Burnout Inventory and baseline generic dose of meditation and yoga. Results showed no significant correlations, though the correlation between T1 emotional exhaustion and yoga did approach significance $(p=.08)$.

Additionally, given that descriptive statistics for dose showed a skewness of 1.45 for baseline meditation frequency, the variable was transformed by logarithm base 10 . 
Correlations between the transformed variable and baseline occupational stress and burnout were not significant.

\section{Research Question 2a: Effects of Treatment Group on Generic Dose-Response;}

Does frequency of generic, teacher self-reported frequency of meditation and movement change over time in the treatment group, as compared to the control group?

Research Question 2a sought to examine the relationship between generic dose of MT (frequency of meditation and movement practice) and outcomes over time, in both the treatment and control groups. To address this question, a series of repeated-measures ANCOVAs were run to examine the relationship of condition and post-program and follow-up generic meditation and movement practice (see Table 11 for details). The first model examined the relationship between group and post-program generic meditation frequency, holding constant baseline generic meditation frequency and years of teaching experience. Analyses showed that post-program generic meditation frequency differed significantly as a function of group, $F(1,87)=58.57, p<.001$, with the treatment group reporting greater frequency of post-program meditation.

Next, we examined the relationship between group and follow-up generic meditation frequency, holding constant baseline generic meditation frequency and years of teaching experience. Results showed that follow-up generic meditation frequency 
differed significantly as a function of group, $F(1,64)=17.36, p<.001$, with the treatment group reporting greater levels of follow-up meditation frequency,

We then examined the relationship between group and post-program generic yoga frequency, holding constant baseline generic meditation frequency and years of teaching experience. Analyses showed that post-program generic yoga frequency differed significantly as a function of group, $F(1,88)=53.04, p<.001$, with the treatment group reporting greater frequency of post-program yoga.

Finally, we examined the relationship between group and follow-up generic yoga frequency, holding constant baseline generic meditation frequency and years of teaching experience. Results showed that follow-up generic yoga frequency did not differ significantly as a function of group, $F(1,63)=1.02, p=.32$.

In sum, results showed that teachers in the mindfulness condition reported meditating more frequently at post-program and at follow-up, and practicing yoga more frequently at post-program, compared to controls.

\section{Research Question 2b: Mediation of Group Effects on Stress and Burnout Through Generic Dose}

Is the relationship between group and stress and burnout at 4-month follow-up mediated by post-program frequency of teachers' self-reported generic meditation and movement practice? 
The second part of Research Question $2 \mathrm{~b}$ examined the possible mediation of the relationship between MT group (T1) and outcomes of stress and burnout at follow-up (T3) by generic dose (meditation or yoga) at post-program (T2). First, we examined if the conditions for mediation were met by examining basic correlations (Baron \& Kenny, 1986 - see Table 12 for details). Results showed a significant correlation between postprogram meditation practice (T2) and follow-up stress (T3), as well as between postprogram yoga (T2) and follow-up stress (T3). No significant correlation was found between either measure of generic dose of practice and symptoms of burnout. Additional analyses examined the correlations between post-program meditation and yoga practice and follow-up emotional exhaustion (a subscale of the MBI symptoms of burnout). These correlations were not significant.

Based on this observed pattern of correlations, two mediational models were then tested using Sobel's (1982) test:

1. MT (T1) $\rightarrow$ Generic Meditation Practice (T2) $\rightarrow$ Occupational Stress (T3)

2. $\mathrm{MT}(\mathrm{T} 1) \rightarrow$ Generic Yoga Practice (T2) $\rightarrow$ Occupational Stress (T3)

We additionally used the bootstrap model proposed by Preacher and Hayes (2004) to confirm the indirect effects the Sobel test produced. Results are presented in Figures 5 and 6, in which the mindfulness condition is coded as " 1 ", and the control group is coded as "2". Results showed that group differences in generic meditation practice at postprogram (T2) did not significantly mediate the relationship between MT condition and follow-up occupational stress (T3). Group differences in teachers' self-reported yoga 
practice at post-program (T2) was found to be a marginally significant predictor of follow-up stress (T3); suggesting a partially mediated effect of yoga practice on stress reduction. Specifically, we see that an increase in generic yoga frequency at postprogram is associated with a marginally significant decrease in stress at follow-up.

Given that these models were not able to include the baseline measures of stress and burnout as control variables, we also examined the relationship between postprogram meditation and yoga frequency and the residual of follow-up stress and burnout after baseline stress and burnout were partialled out. Correlations showed no relationship between the residual of follow-up burnout and post-program meditation or yoga frequency, but significant correlations were seen between follow-up stress and condition, and post-program meditation and yoga frequency. Mediational models were then tested using the residual of follow-up stress. Results were similar to those found in the above mediational models. The relationship between condition and follow-up stress was not significantly mediated by post-program meditation. There was some evidence for a partial mediation between condition, post-program yoga, and follow-up stress (see figure 5). Thus, we see some evidence that stress reduction in the mindfulness condition was partially caused by increased frequency of generic yoga.

\section{Research Question 3: Program Specific Dose-Response Effects on Stress and Burnout Randomized to Mindfulness Condition}

Research Question 3a aimed to answer if individual differences in teachers' program-specific dose (i.e., the number of minutes in-class and home practice that 
teachers engage in during a 9 week mindfulness training program) was associated with the amount of benefit they receive from the program in terms of reductions in occupational stress and burnout at the end of the program (T2) and 4 months later (T3) at the beginning of a new school year?

Research question 3a sought to explore whether dose of program-specific mindfulness and mindful movement practice, assessed as number of minutes of program attendance and home practice, among teachers in the treatment group only, was associated with changes in their levels of self-reported stress and burnout at T2 and T3, controlling for baseline levels of stress and burnout. Thus, this question examined the relationship between both attendance in the mindfulness training program (in-class specific dose) and amount of home practice completed (at-home specific dose) and changes in occupational stress and burnout over time. To answer these questions, we conducted a series of multiple regression analyses with those in the mindfulness treatment condition only using baseline measures of stress and burnout and years of teaching experience as covariates, and the specific-dose measures as predictors of stress and burnout at T2 and T3. Results are presented in Table 13.

The first series of multiple regression analyses assessed the relationship between minutes of in-class program attendance and home practice and stress at post-program and follow-up, controlling for baseline stress and years of teaching experience. Results showed that neither measure of program-specific dose significantly predicted postprogram occupational stress after accounting for the covariates. Baseline stress was the 
only significant predictor of teachers' stress at post-program $(B=.68, t(32)=5.50, p<$ $.001)$ and follow-up $(B=.64, t(30)=4.63, p<.001)$ in these analyses.

The second series of multiple regression analyses assessed the relationship between minutes of program attendance and program-specific home practice and teachers' symptoms of occupational burnout at post-program and follow-up. Again, neither measure of program-specific dose significantly predicted teacher burnout. Baseline levels of burnout was the only significant predictor at post-program $(B=.773$, $t(31)=6.03, p<.001)$ and follow-up) $B=.61, t(30)=3.96, p<.001)$ in these analyses.

Additional analyses examined the relationship between minutes of program attendance and program-specific home practice and teachers' symptoms of emotional exhaustion. Results showed that neither measure of program-specific dose significantly predicted teacher burnout.

Additionally, given that program-specific home practice showed high skewness (1.96) and kurtosis (4.19), the variable was transformed by logarithm base 10. This transformation reduced skewness, but increased kurtosis. Analyses rerun with the transformed variable showed similar results; namely, that the variable did not significantly predict post-program or follow-up stress or burnout.

In summary, the results of a series of multiple regression analyses showed that minutes of in-class and at-home program-specific dose mindfulness practice did not 
significantly predict stress or burnout at $\mathrm{T} 2$ or $\mathrm{T} 3$, after controlling for baseline measures and covariates (Table 13 for details).

\section{Research Question 3b: Threshold analysis}

The final research question examined the possibility of a change in the relationship between program-specific dose and outcomes at a certain dose. A median split was conducted to differentiate "low" and "high" MT dose groups. Correlations between total program dose and post-program occupational stress and burnout were not significant. Repeated-measures ANCOVAs were run to examine the relationship between total program dose and follow-up occupational stress and burnout, controlling for baseline measures of the outcomes as well as teachers' years of teaching experience. Results showed that total program dose did not significantly predict follow-up occupational stress or burnout. 


\section{Chapter 6. Discussion}

Mindfulness Training has been proposed as an efficacious and under-researched form of stress management for teachers. Yet, research on the dose of mindfulness training needed to achieve efficacy is unclear. This is due to measurement and program implementation differences, as well as the early state of research in this area. The current study contributes to an increased understanding in a growing body of literature of the relationship between generic and program specific forms of dose of contemplative practice (e.g., meditation, movement) and program-specific outcomes such as occupational stress and burnout reduction. It is among of the few randomized, controlled trails to specifically examine this relationship generally, and in relationship to teachers specifically. Given the increasing demands placed on teachers' already busy schedules, it is vital to increase understanding of the relationship between amount of training received and outcomes

Overall, results on generic doses of teachers' self-reported frequency of meditation and movement practice were mixed. First, results showed that teachers' randomization to a mindfulness training was associated with increased self-reported frequency of engagement in meditation and movement practices from baseline to postprogram and follow-up compared to controls. In sum, mindfulness training was associated with increases in generic measures of engagement in contemplative practices over time. We also found that teachers' self-reported frequency of meditation and movement at post-program were significantly correlated with subsequent levels of 
occupational stress, and a more formal statistical test showed that it was frequency of practicing yoga, but not meditation, that partially mediated the relationship between randomization to mindfulness training condition and reductions in occupational stress at follow-up. Additionally, when the effect of baseline stress was partialled out of follow-up stress and the residual was assessed in this mediational model, the results held. These results provide additional support for a causal relationship between MT, generic yoga dose, and occupational stress reduction. These results suggest program-related increases in movement practice are one of the pathways of influence by which mindfulness training for teachers reduces job stress.

These results, similar to the results of the meta-analysis on workplace stress reduction programs - show these programs can reduce stress (Richardson and Rothstein, 2008). These results also show mindfulness training can change behaviors like engagement in contemplative practices. Our results with regard to changes in contemplative movement practices are consistent with those obtained by Carmody and Baer (2008) in their studies of the key factors mediating stress-reduction effects among participants in MBSR (Mindfulness-based Stress Reduction). Carmody and Baer showed that total practice time of yoga was significantly correlated with greater change in psychological well-being, and anxiety, among other outcomes. They posit that the order of specific home practices assigned may influence outcomes. In their study, for example, they suggest that, "it may be that the time participants spent in practice of the body scan prepared them to be more mindful of their bodily sensations during the yoga, and hence 
obtained more benefit from the yoga practice than if they had come to it without prior mindfulness practice." (pg. 31). An additional thought is that, given the inherently visible quality of yoga and mindful movement, it may be easier for MT instructors to teach and scaffold the practice than it is to teach a more internal practice, such as mindful meditation. This increased teaching ability would likely improve participants' home practice, and ultimately the benefit they receive from it. MBSR is the core of the program under investigation here, so these findings converge nicely. Movement may be particularly important for teachers because it incorporates both the qualities of mindful attention and awareness, as well as mild exercise. This "two for one" quality might prove to be doubly efficacious and efficient for teachers seeking to reduce stress.

That frequency of meditation increased as a function of training is also an important finding regarding program efficacy, although this group difference in frequency of meditation at post-program did not mediate program-related decreases in stress among the treatment group at follow-up. Promoting lifestyle changes, broadly defined, like meditating a bit more frequently, may help to reduce stress over a longer time period than that examined in this study.

On the other hand, measures of program specific dose of mindfulness training conceptualized as individual differences in the number of minutes participating teachers practiced mindfulness in class and at home - were not related to changes in occupational stress and burnout from baseline to post-program or follow-up. These null findings may have been a result of restricted ranges of in both measures of specific dose examined in 
this study in that most teachers attended most sessions and reported completing a majority of the home practice time (see Figures 3-4). These results are similar to other studies using expert teachers (Davidson et al., 2003; Kemeny et al., 2011) in which there was restricted range in program-specific dose and little relation of dose to significant outcomes of the program. Examining program-specific dose response relations in different ways, in larger samples with more variability, is warranted in future studies of teachers and individuals in mindfulness trainings more generally. In the next section, I discuss study limitations. These issues are discussed more below.

\section{Limitations and Future Directions}

This study had several limitations that are important to address in future research. Below, I discuss issues related to design, measurement, thresholds, and teacher subgroups.

External Validity One limitation in this study is that of participants' self-selection into the program. Participants volunteered to take part in the study, with the understanding that they would be part of either the MT treatment group, or a waitlistcontrol group that would ultimately retrieve the treatment. It can be suggested then, that participants are more likely than the general population to be interested in and motivated to receive benefit from a MT program. This thus limits generalizability of our findings to those who are at least minimally interested in mindfulness training, or those who are open minded. 
Internal Validity An additional consideration is the lack of randomization of dose in this study. Participants self-selected the doses of both generic meditation and yoga and program-specific MT that they received, rather than being randomized to, for example, low, medium and high dose conditions. This limits the causal implications of our findings regarding the relationship of dose and outcomes. Additional variables could affect this relationship; future studies should examine this relationship with dose randomized, to boost internal validity.

Measurement of Dose and Quality of Program Elements. An additional limitation in this study that may have affected the results was the restriction to self-report survey measures of the outcomes of interest. Specifically, occupational stress and burnout were measured solely by self-report and are therefore vulnerable to issues of response bias. It is possible that participants came to like the MT instructor, and therefore (whether intentionally or not) inflated their self-reported benefits from the program.

Including physiological measures of stress in future studies and reports by key informants in teachers' lives are two ways to address this limitation in future research. Future studies might include measures of stress such as salivary cortisol, blood pressure and heart rate variability (Weitzman et al, 1971; Perloff et al, 1993; Fox et al, 2007). If effects of the study could be replicated using these additional physiological variables, it would lead to increased support for the proposed link between mindfulness and occupational health, and could lead to further research on the ways in which the program 
could ultimately reduce health care risks for teachers and health care costs for school districts (e.g., Roeser et al., 2012).

Similarly, future studies should examine how program dose is related to outcomes using an expanded set of measures. This study conceptualizes dose as a marker of amount of program engagement, as well as a measure of opportunity to learn. Here, dose is operationalized as quantity, or amount of time (including amount of time of MT program attendance, and self-reported amount of time spent in home practice of MT) in which there is an opportunity to learn. Additional measures, such as daily diaries and experience sampling methods can provide alternate ways to quantify participants' self-report of participation in MT. Daily diary phone applications may be an especially effective way of tracking how much and what specific practice is engaged in daily, though care should be taken to avoid adding burden to the extent that participation becomes discouraged.

An alternate metric on which to measure dose is quality of program engagement and instruction. That is, how do differences in quality of MT received relate to outcomes? It may be that instructor quality is especially important, such that expert program instructors, rather than novices, are needed to produce significant benefits. Expert instructors may be able to produce a higher quality of engagement in participants, such that even shorter programs could inspire fruitful engagement and significant occupational health benefits. There may thus be a tradeoff between quantity and quality, such that one can compensate for the other. Alternately, quality may moderate the relationship between quantity and outcomes. Participants with busy lives may be more willing to spend their 
time with an instructor who they perceive as high quality. In this way, higher quality instructors might drive higher doses of MT received (within the constraints of the specific program).

Related to this question is a question of which specific components of MT are most beneficial with regard to improving occupational health. For example, home practice may be especially impactful, indicating the need for participants to practice at least a certain amount (or with a certain frequency) of MT on their own to receive significant benefits. Alternately, it might be the case that differences in home practice have little to do with stress and burnout reduction, and that it is the guided, group practice received during program sessions that is most beneficial. This finding would have implications for the structure of such a course and its ability to foster change in the long term.

Further research might include increased measures of program implementation related to these factors. It is clear that differences in these aspects of program implementation can result in large differences in program outcomes (Durlak \& DuPre, 2008). Especially given how little research has currently been done on the evaluation of this kind of professional development program for teachers, an important direction for future research is the continuation of evaluation of program dosage (including the provision of booster sessions of the program), fidelity, differentiation and adaptation, as well as other elements of implementation. This will provide further clarification as to the specific components of the program that are most effective for most participants, as well 
perhaps components that are especially effective for certain subgroups, such as those teachers who are more highly stressed initially, or newer teachers who have not yet firmly established particular self-regulation strategies during stressful classroom situations. This will also aid program developers in producing a program that is feasible for teachers wishing to participate, cost effective for schools wishing to provide the program, and effective with regard to the development of habits of mind, the reduction of stress and the increase in wellbeing.

Future studies would also do well to systematically vary different measures of dose, including quantity, and quality of various components of the program, to further clarify their relationship to each other, as well as to important program outcomes, including occupational health. It may be, for example, that quantity and quality of dose can act in a compensatory fashion, such that increases in one can compensate for decreases in the other. Alternately, it may be the case that high quality and increased amount of time are needed to see the greatest amount of benefit. For those short on time, such as teachers, this is an important question when considering feasibility of an intervention.

Thresholds of Program Impact on Stress. Identifying the threshold of amount of MT related to decreases in teacher stress and burnout is of interest to policy makers and school administrators making decisions regarding teacher PD. Traditional MBSR programs are structured to provide 36 hours of training. With this wide range of instruction time comes a wide range in participants' investment, making the study of the 
threshold of MT needed to see a reduction in teacher stress and burnout an important goal. It is possible that the benefit of MT will begin to taper off to a more gradual rate after a certain number of hours of training; further training after this point would not be necessary for teacher benefit, nor would it be cost effective. (Ericsson \& Charness, 1994) have shown that it take about 50,000 hours to reach expertise in a specific skill; while true expertise would not be a feasible goal for teacher PD programs, it is possible that it takes only a few hours to reach a level of moderate proficiency, and to see benefits, such as stress and burnout reduction and increases in well-being. Alternately, it is possible that a minimum number of hours of training must happen in order for participants to see any benefit at all. This finding would mean that MT programs would not be cost effective unless it contained at least this number of hours of training. Though this study did not find significant relationships between dose and outcomes, it is still possible that there is a "sweet spot" of dose (including both quantity and quality of dose) that maximizes benefit gained and minimizes time spent in instruction. Future studies should continue a systematic examination of this question.

Teacher Subgroups Studies. Guglielmi and Tatrow (1998) have discussed many possible individual difference variables acting as mediators and moderators of the relationship between stress and negative health outcomes, including gender, age, ethnicity, and teacher variables such as subject, grade and years of experience. Further research should investigate the potential moderation or mediation of these variables on the relationship between dose and program effects. Additionally, little is yet known about 
the development of mindfulness-based skills among teachers at different stages of their careers. Subgroup studies among early and later career teachers in the kinds of research questions examined in this thesis are also warranted.

\section{Summary}

Research suggests that teaching is a highly stressful profession (Chaplain, 2008; Farber, 1999). Many teachers classify their job as "highly stressful", and many exhibit at least some symptoms of burnout, as well as turnover intentions, and actual turnover as they leave the profession. Though not the only reason, one of the main reasons cited for teacher attrition is occupational stress (Montgomery \& Rupp, 2005). Stress and related negative physical, physiological, and career outcomes is clearly an important issue in the teaching profession and for educational leaders.

In this study, we explored how teachers' engagement in contemplative practices, like mindfulness and yoga, offered as a district professional development program, helped teachers to develop the skills they need to manage stress and maintain resilience on and off the job. Preliminary evidence suggests that engagement in contemplative practices such as mindfulness meditation and yoga, can assist teachers, a group known to experience high levels of occupational stress and burnout, to learn how to regulate emotion and manage stress more effectively (Kemeny et al, 2012; Roeser et al, 2013, Winzelburg \& Luskin, 1999, etc.). To date, however, little research has been done on the question of how frequently or how much time teachers need to invest in mindfulness 
meditation or yoga practice (i.e., "dose and duration") to see stress reduction effects (i.e., "response").

The purpose of this study was to examine dose-response relationships between teachers' amount and frequency of engagement in mindfulness and yoga practice and their levels of occupational stress and burnout. Results showed no significant findings regarding these relationships, but possible explanations are discussed, and future directions are outlined. Looking at the future of research on this topic, we see that there is much to learn about the role of mindfulness in education. A better scientific understanding of the relationship of mindfulness and mental health outcomes will have important implications for those in education. Specifically, studies that further clarify the relationship of program dose and outcomes will help find the feasibility/efficacy "sweet spot" at which teachers are able to attend the full program (without being overwhelmed at the time commitment) and receive benefit (without attending a program that is so short that it does not produce real change). As stated previously, teachers' jobs are demanding, and their lives are busy. An increased understanding of the relationship between program dose and outcomes can provide important information to school districts seeking to improve their teachers' occupational health, engagement in teaching, student engagement, and costs related to health care and teacher retention through evidence based programs (Jennings \& Greenberg, 2009; Roeser et al., 2012). 


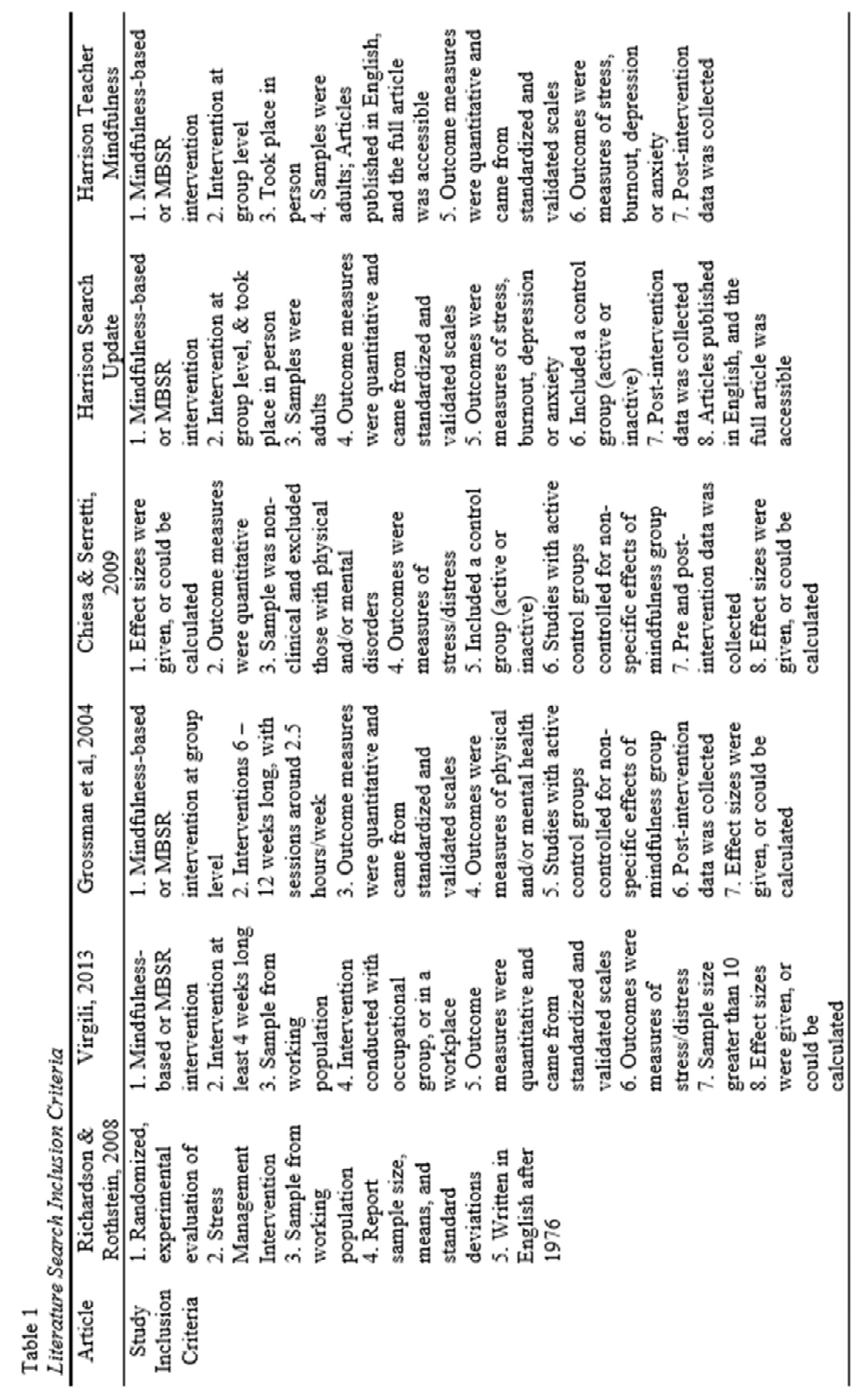




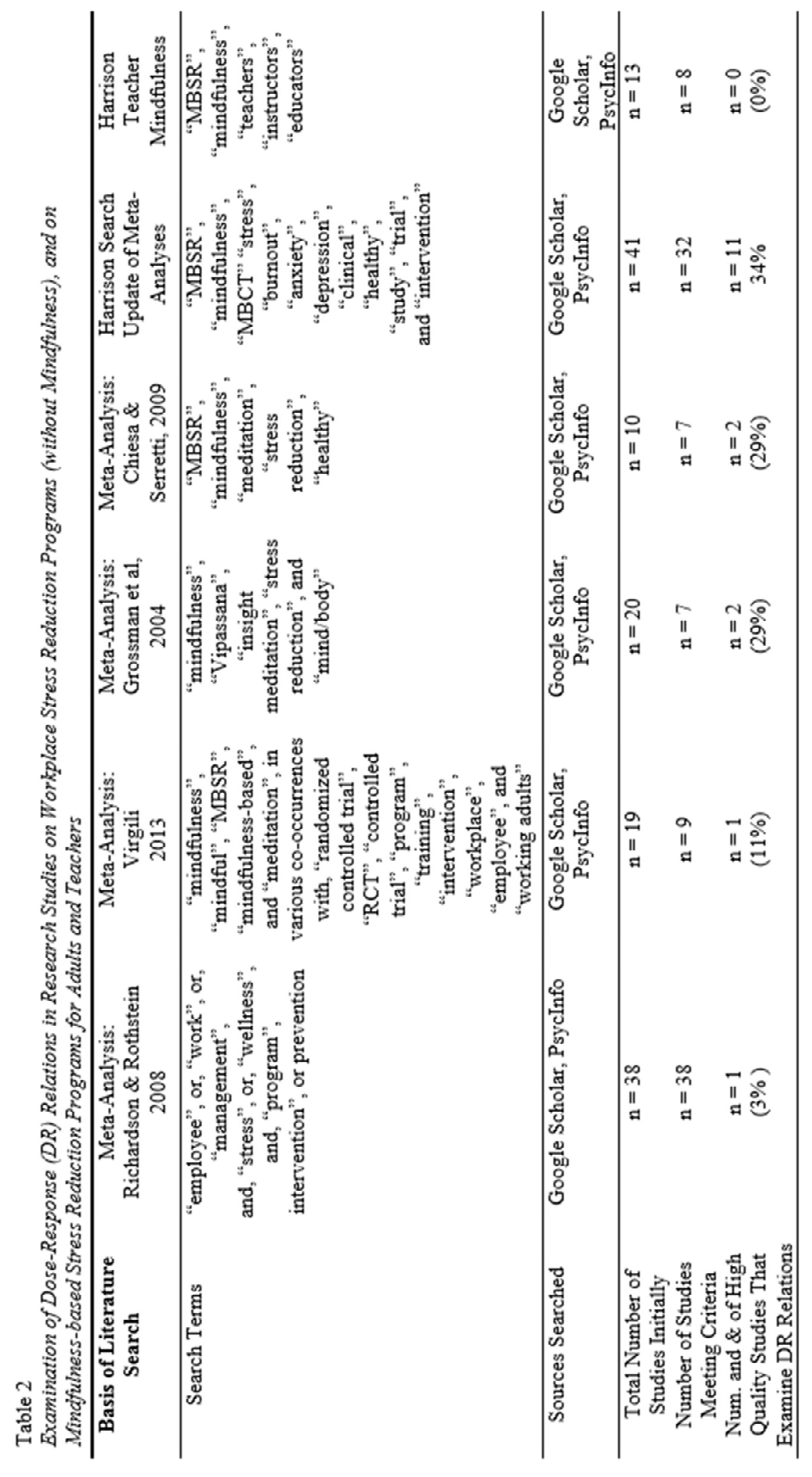


Table 3

Virgili, 2013: High Quality Studies

\begin{tabular}{ccc}
\hline Study Name & Dose/Response Examined & Findings \\
\hline Davidson et al, 2003 & Yes & Null \\
& $13 \%$ & \\
Josefsson et al, 2012 & No & - \\
Klatt et al, 2009 & No & - \\
Manotas, 2012 & No & - \\
Pipe et al, 2009 & No & - \\
West, 2011 & No & - \\
Wilson, 2012 & No & - \\
Wolever et al, 2012 & No & - \\
& $87 \%$ & \\
\hline
\end{tabular}

Table 4

Grossman, 2004: High Quality Studies

\begin{tabular}{ccc}
\hline Study Name & Dose/Response Examined & Findings \\
\hline Speca et al, 2000 & Yes & Positive \\
Sephton et al, 2001 & Yes & Mixed, sig. (positive) \\
& & \& ns \\
Murphy, 1995 & $29 \%$ & - \\
Perkins, 1998 & No & - \\
Shapiro et al, 1998 & No & - \\
Williams, Larkin et al, 2001 & No & - \\
Williams, Kolar et al, 2001 & No & - \\
& No & \\
\hline
\end{tabular}

Table 5

Chiesa \& Serretti, 2009: High Quality Studies

\begin{tabular}{ccc}
\hline Study Name & Dose/Response Examined & Findings \\
\hline Jain et al, 2007 & Yes & Null \\
Vieten \& Astin, 2008 & Yes & Null \\
Shapiro et al, 2005 & $29 \%$ & \\
Astin, 1997 & No & - \\
Shapiro et al, 1998 & No & - \\
Cohen-Katz, 2005 & No & - \\
Klatt et al, 2008 & No & - \\
& No & - \\
\hline
\end{tabular}


Table 6

Harrison Update, High Quality Studies

\begin{tabular}{ccc}
\hline Study Name & Dose/Response Examined & Findings \\
\hline Biegel et al, 2009 & Yes & Positive \\
Geschwind et al, 2012 & Yes & Positive \\
Hoffman et al, 2012 & Yes & Positive \\
Carson et al, 2004 & Yes & Positive \\
Daubenmier et al, 2012 & Yes & Positive (marg. sig.) \\
Gross et al, 2010 & Yes & Mixed \\
Lengacher et al, 2009 & Yes & Mixed \\
Guardino et al, 2013 & Yes & Null \\
De Vibe et al, 2013 & Yes & Null \\
Hou et al, 2013 & Yes & Null \\
Nyklicek \& Kujipers, 2008 & Yes & Null \\
Arch et al, 2013 & No & - \\
Bedard et al, 2013 & No & - \\
Branstrom et al, 2010 & No & - \\
Daubenmier et al, 2011 & No & - \\
Gayner et al, 2011 & No & - \\
Grossman et al, 2010 & No & - \\
Hartmann et al, 2012 & No & - \\
Henderson et al, 2012 & No & - \\
Henderson et al, 2013 & No & - \\
Jazaieri et al, 2012 & No & - \\
Kocovski et al, 2013 & No & - \\
Parwani et al, 2013 & No & - \\
Pinniger et al, 2012 & No & - \\
Shahar et al, 2010 & No & - \\
Sherr, 2010 & No & - \\
Vollestad et al, 2011 & No & - \\
Williams et al, 2013 & No & - \\
Wurtzen et al, 2013 & No & - \\
Nyklicek et al, 2013 & No & - \\
Robins et al, 2012 & No & - \\
Shapiro et al, 2011 & No & - \\
Warnecke et al, 2011 & No & No \\
Whitebird et al, 2012 & & - \\
& & - \\
\hline
\end{tabular}


Table 7

HQ Studies Examining Dose/Response: Assigned and Mean Doses

\begin{tabular}{|c|c|c|c|c|}
\hline $\begin{array}{c}\mathrm{HQ}+\text { DR Study } \\
\text { Name }\end{array}$ & Definition of Dose & $\begin{array}{l}\text { Assigned Total } \\
\text { Dose in Minutes }\end{array}$ & $\begin{array}{c}\text { Mean Total } \\
\text { Reported Dose in } \\
\text { Minutes }\end{array}$ & Finding \\
\hline Biegel et al, 2009 & $\begin{array}{l}\text { Total Num. Days of } \\
\text { Home Practice, } \\
\text { Avg. Min. Weekly } \\
\text { Home Practice }\end{array}$ & 2920 & - & Positive \\
\hline $\begin{array}{l}\text { Geschwind et al, } \\
2012\end{array}$ & $\begin{array}{l}\text { Avg. Min. Daily } \\
\text { Home Practice }\end{array}$ & 4560 & 1568 & Positive \\
\hline Hoffman et al, 2012 & $\begin{array}{l}\text { Class contact hours, } \\
\text { home practice hours }\end{array}$ & 3240 & 2222 & Positive \\
\hline Carson et al, 2004 & Daily Min. Practice & 3780 & - & Positive \\
\hline $\begin{array}{c}\text { Daubenmier et al, } \\
2012\end{array}$ & Attendance Rates & 3390 & - & $\begin{array}{l}\text { Positive } \\
\text { (marg. } \\
\text { sig.) }\end{array}$ \\
\hline Sephton et al, 2001 & $\begin{array}{c}\text { Number of practice } \\
\text { occasions }\end{array}$ & 3780 & - & $\begin{array}{l}\text { Mixed, } \\
\text { positive } \\
\text { and null }\end{array}$ \\
\hline Speca et al, 2000 & $\begin{array}{c}\text { Attendance Rates \& } \\
\text { Avg. Min. Daily } \\
\text { Home Practice }\end{array}$ & $630(\mathrm{CC})$ & 2108 (HP \& CC) & $\begin{array}{l}\text { Mixed, } \\
\text { positive } \\
\text { and null }\end{array}$ \\
\hline Gross et al, 2010 & $\begin{array}{l}\text { Avg. Min. Daily } \\
\text { Home Practice }\end{array}$ & $1620(\mathrm{CC})$ & 1624 & Mixed \\
\hline $\begin{array}{l}\text { Lengacher et al, } \\
2009\end{array}$ & $\begin{array}{c}\text { Program } \\
\text { Compliance, Total } \\
\text { Min. Home Practice }\end{array}$ & 2610 & 1077 (HP) & Mixed \\
\hline $\begin{array}{c}\text { Davidson et al, } \\
2003\end{array}$ & $\begin{array}{l}\text { Duration and } \\
\text { Frequency of Home } \\
\text { Practice }\end{array}$ & 4500 & 320 (HP) & Null \\
\hline Jain et al, 2007 & $\begin{array}{c}\text { Total Hours Home } \\
\text { Practice }\end{array}$ & $360(\mathrm{CC})$ & 316 (HP) & Null \\
\hline $\begin{array}{c}\text { Vieten \& Astin, } \\
2008\end{array}$ & Attendance Rates & 2080 & $864(\mathrm{CC})$ & Null \\
\hline $\begin{array}{l}\text { Guardino et al, } \\
2013\end{array}$ & $\begin{array}{c}\text { Attendance Rates, } \\
\text { Amt. of Home } \\
\text { Practice }\end{array}$ & 1434 & $570(\mathrm{CC})$ & Null \\
\hline De Vibe et al, 2013 & $\begin{array}{l}\text { Attendance Rates } \\
\text { and Total Min. } \\
\text { Home Practice }\end{array}$ & 2160 & - & Null \\
\hline Hou et al, 2013 & $\begin{array}{c}\text { Attendance Rates } \\
\text { and Avg. Min. } \\
\text { Weekly Home } \\
\text { Practice }\end{array}$ & 3480 & 1085 & Null \\
\hline $\begin{array}{c}\text { Nyklicek \& } \\
\text { Kujipers, } 2008\end{array}$ & $\begin{array}{l}\text { Attendance Rates } \\
\text { and Avg. Num. } \\
\text { Weekly Home } \\
\text { Practice Sessions }\end{array}$ & 3560 & 777 (CC) & Null \\
\hline $\mathrm{CC}=$ class contact $\mathrm{c}$ & only; HP = home & ce dose only & & \\
\hline
\end{tabular}


Table 8

MT Program Session Content and Length

\begin{tabular}{|c|c|c|}
\hline Session & Content & Session Length in Minutes \\
\hline 1 & Introduction & $90(1.5 \mathrm{hrs})$ \\
\hline 2 & Perceptions & $330(5.5 \mathrm{hrs})$ \\
\hline 3 & Responding versus reacting & $150(2.5 \mathrm{hrs})$ \\
\hline 4 & $\begin{array}{c}\text { Pleasant, unpleasant and } \\
\text { neutral affect }\end{array}$ & 150 \\
\hline 5 & Exploring forgiveness & 150 \\
\hline 6 & Working with conflict & 150 \\
\hline 7 & Compassion and kindness & 150 \\
\hline 8 & Working with anger & $360(6 \mathrm{hrs})$ \\
\hline 9 & Silent retreat & 150 \\
\hline 10 & Working with fear & 150 \\
\hline 11 & Beginnings and endings & \\
\hline
\end{tabular}




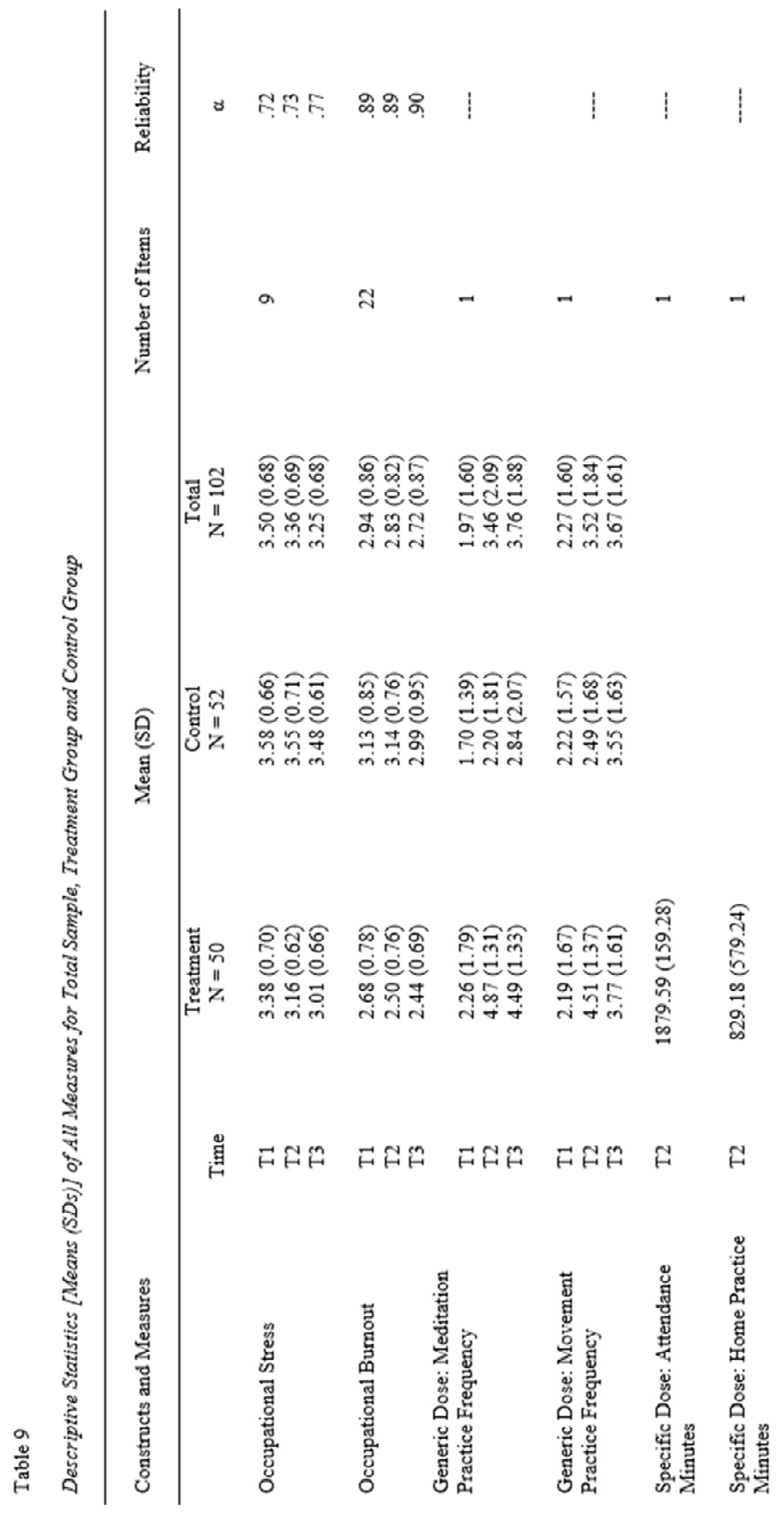


Table 10.

Research Question 1: Descriptive Statistics and Bivariate Correlations Between All Teachers' Self-Reported Meditation and Yoga Practice and Levels of Job Stress and Burnout at Baseline

\begin{tabular}{lcccc}
\hline Baseline Measures & 1 & 2 & 3 & 4 \\
\hline 1. Frequency Meditation & ----- & & & \\
Practice & & & & \\
2. Frequency Yoga Practice & $.48^{* *}$ & ----- & & \\
3. Occupational Stress & -.02 & -.11 & ------ & \\
4. Occupational Burnout & -.03 & $-.22^{*}$ & $.65^{* *}$ & ----- \\
& & & & \\
\hline M & 1.97 & 2.21 & 3.48 & 2.91 \\
$(\mathrm{SD})$ & $(1.61)$ & $(1.61)$ & $(0.68)$ & $(0.85)$ \\
\hline
\end{tabular}

Note. $N=99 . * * p<.01$.

Table 11

Standardized Betas and Bivariate Correlations for Both Groups: Research Question 2a: Differences in Generic Dose of Meditation and Yoga Frequency Over Time

\begin{tabular}{|c|c|c|c|c|}
\hline Predictor & $\begin{array}{l}\text { Mindfulness } \\
\text { Group } \\
\text { M (SD) }\end{array}$ & $\begin{array}{l}\text { Control } \\
\text { Group } \\
\mathrm{M}(\mathrm{SD})\end{array}$ & $F$ & $d f$ \\
\hline Model 1 & & & & \\
\hline $\begin{array}{l}\text { T2 Meditation Frequency } \\
\text { T1 Meditation Frequency }\end{array}$ & $4.87(1.31)$ & $2.20(1.81)$ & $\begin{array}{l}58.57 * * \\
24.64 * *\end{array}$ & 1,87 \\
\hline $\begin{array}{l}\text { Years of Experience } \\
\text { Model } 2\end{array}$ & & & .52 & \\
\hline $\begin{array}{l}\text { T3 Meditation Frequency } \\
\text { T1 Meditation Frequency } \\
\text { Years of Experience }\end{array}$ & $4.49(1.34)$ & $2.84(2.07)$ & $\begin{array}{c}17.36 * * \\
19.61 * * \\
4.79 *\end{array}$ & 1,64 \\
\hline $\begin{array}{l}\text { T2 Yoga Frequency } \\
\text { T1 Yoga Frequency } \\
\text { Years of Experience } \\
\text { Model } 4\end{array}$ & $4.51(1.37)$ & $2.49(1.68)$ & $\begin{array}{c}53.04 * * \\
30.46 * * \\
.80\end{array}$ & 1,88 \\
\hline $\begin{array}{l}\text { T3 Yoga Frequency } \\
\text { T1 Yoga Frequency } \\
\text { Years of Experience }\end{array}$ & $3.77(1.61)$ & $3.55(1.63)$ & $\begin{array}{c}1.02 \\
18.23 * * \\
.03\end{array}$ & 1,63 \\
\hline
\end{tabular}


Table 12.

Research Question 2b: Bivariate Correlations Between All Teachers' Self-Reported Post-Program and Follow-Up Meditation and Yoga Practice, Levels of Job Stress and Burnout and Condition

\begin{tabular}{lcccc}
\hline Measures & 1 & 2 & 3 & 4 \\
\hline 1. Condition $(1=$ exp, $2=$ control) & ---- & & & \\
2. Frequency of Meditation Practice & $-.65^{* *}$ & ---- & & \\
3. Frequency of Yoga Practice & $-.55^{* *}$ & $.68^{* *}$ & ---- & \\
4. Occupational Stress & $.35^{* *}$ & $-.31^{* *}$ & $-.36^{* *}$ & ---- \\
5. Occupational Burnout & $.32^{* *}$ & -.07 & -.17 & $.62^{* *}$ \\
\hline Note. ${ }^{* * p}<.01$. & & & &
\end{tabular}

Table 13

Standardized Betas and Bivariate Correlations for Treatment Group Only:

Research Question $3 a$ and 3b: Total in Class Program Attendance Minutes and

Total Home Practice Minutes Predicting Post-program and Follow-up

Occupational Stress, and Burnout

\begin{tabular}{|c|c|c|c|c|}
\hline \multirow{4}{*}{ Predictor } & \multicolumn{4}{|c|}{ Outcomes } \\
\hline & \multicolumn{2}{|c|}{ Occupational Stress } & \multicolumn{2}{|c|}{ Occupational Burnout } \\
\hline & $\mathrm{T} 2$ & $\mathrm{~T} 3$ & $\mathrm{~T} 2$ & $\mathrm{~T} 3$ \\
\hline & $\beta(r)$ & $\beta(r)$ & $\beta(r)$ & $\beta(r)$ \\
\hline Years of Experience & $0.23(0.22)$ & $0.16(0.16)$ & $0.02(-0.11)$ & $\begin{array}{l}-0.10(- \\
0.20)\end{array}$ \\
\hline Baseline Measure & $0.68 * *(0.66)$ & $0.64 * *(0.62)$ & $0.77 * *(0.74)$ & $\begin{array}{l}0.61 * * \\
(0.55)\end{array}$ \\
\hline $\begin{array}{l}\text { Program Attendance } \\
\text { Minutes }\end{array}$ & $0.13(0.14)$ & $-0.18(-0.17)$ & $-0.12(0.02)$ & $\begin{array}{l}-0.16(- \\
0.08)\end{array}$ \\
\hline $\begin{array}{l}\text { Home Practice } \\
\text { Minutes }\end{array}$ & $-0.12(0.01)$ & $-0.05(0.01)$ & $-0.04(0.16)$ & $\begin{array}{l}-0.17(- \\
0.02)\end{array}$ \\
\hline F value & $8.66^{* *}$ & $6.07 * *$ & $9.74 * *$ & $4.46^{* *}$ \\
\hline df & 4,32 & 4,30 & 4,31 & 4,30 \\
\hline Adjusted $\mathrm{R}^{2}$ & .46 & .37 & .50 & .29 \\
\hline
\end{tabular}

Note. $N=38$. Baseline Measure = value for baseline measure of each outcome (occupational stress and burnout).

$* p<.05 . * * p<.01$. 


\section{Figures}

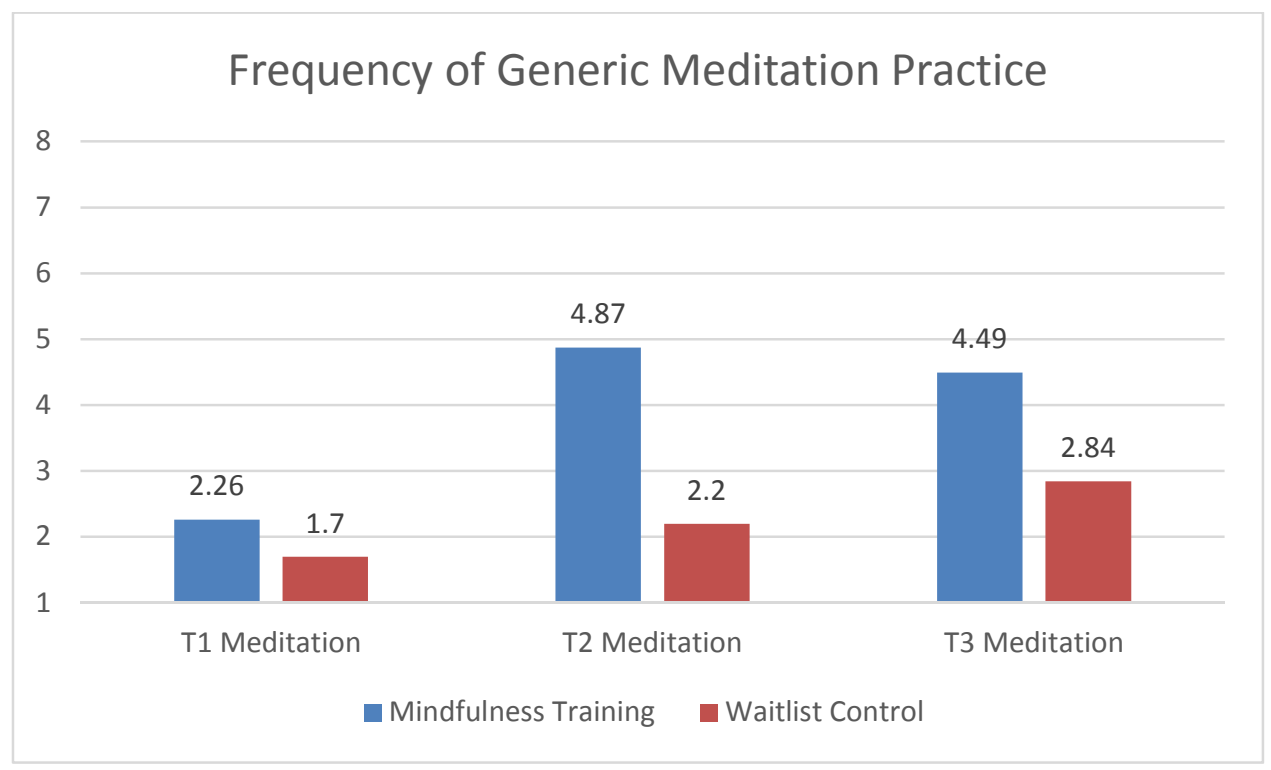

Figure 1. Frequency of generic dose of meditation practice over time by group. 1 = "Never/less than once per year", 5 = "Several times a week", 8 = Several times a day" T1 MT group, $\mathrm{N}=46$; T2 $\mathrm{MT}$ group, $\mathrm{N}=47$, T3 $\mathrm{MT}$ group, $\mathrm{N}=40$

T1 Control group, $\mathrm{N}=50$, T2 Control group, $\mathrm{N}=51$, T3 Control group, $\mathrm{N}=32$

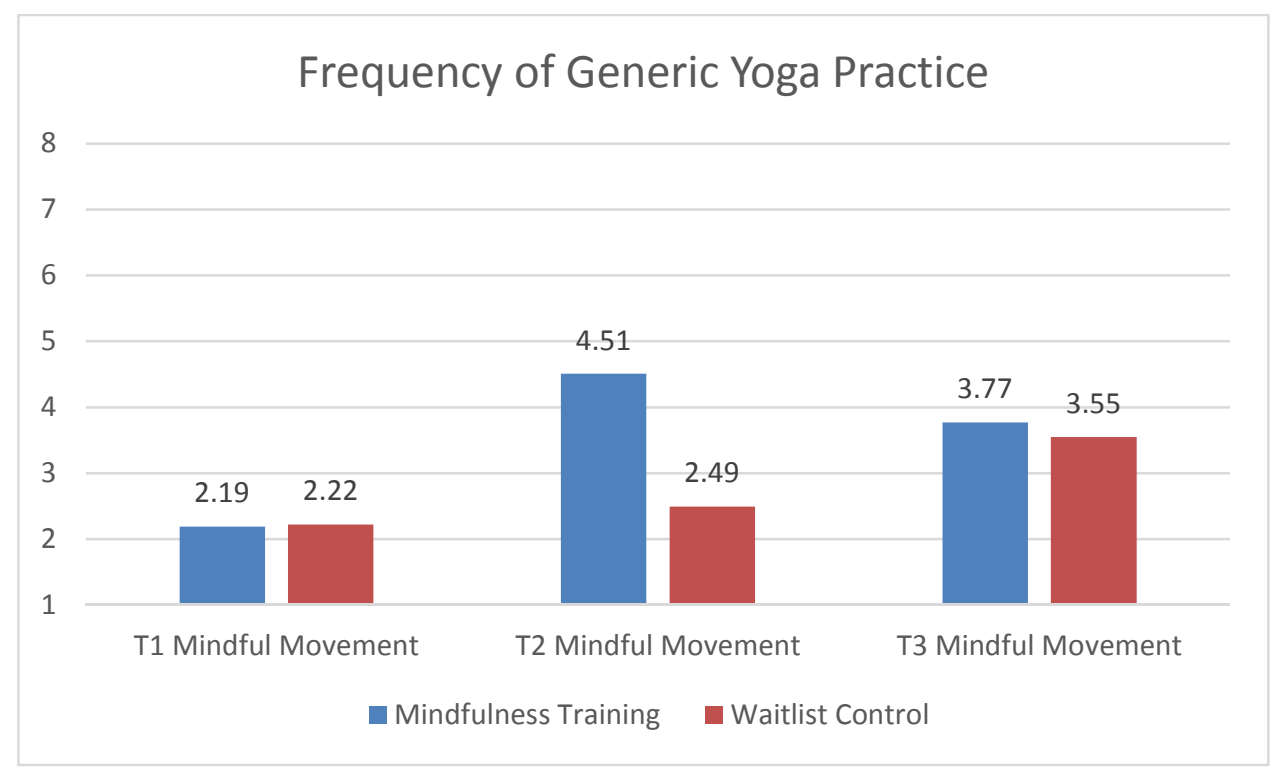

Figure 2.Research Question 2a: Frequency of generic dose of yoga over time by group. $1=$ "Never/less than once per year", $5=$ "Several times a week", $8=$ Several times a day" T1 MT group, $\mathrm{N}=48$; T2 $\mathrm{MT}$ group, $\mathrm{N}=47$, T3 MT group, $\mathrm{N}=37$

T1 Control group, $\mathrm{N}=49$, T2 Control group, $\mathrm{N}=51$, T3 Control group, $\mathrm{N}=32$ 


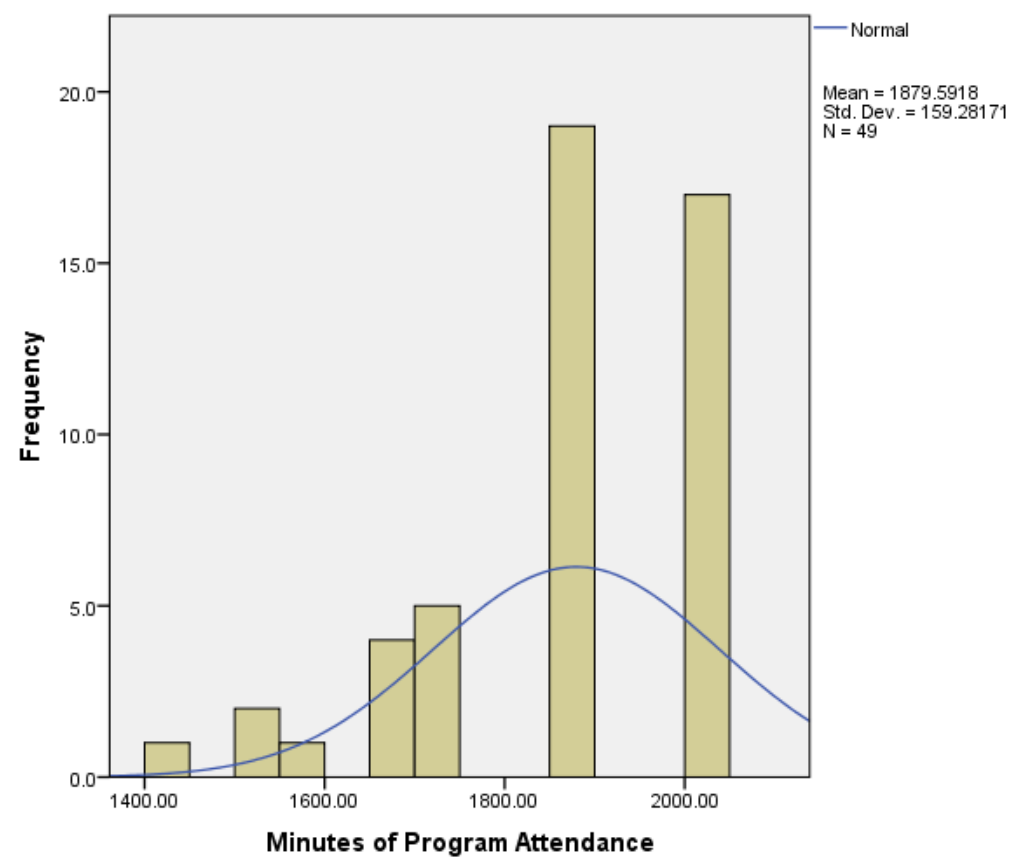

Figure 3. Histogram of individual differences in program-specific dose, measured as minutes of mindfulness program attendance among teachers randomized to mindfulness condition $(n=43)$.

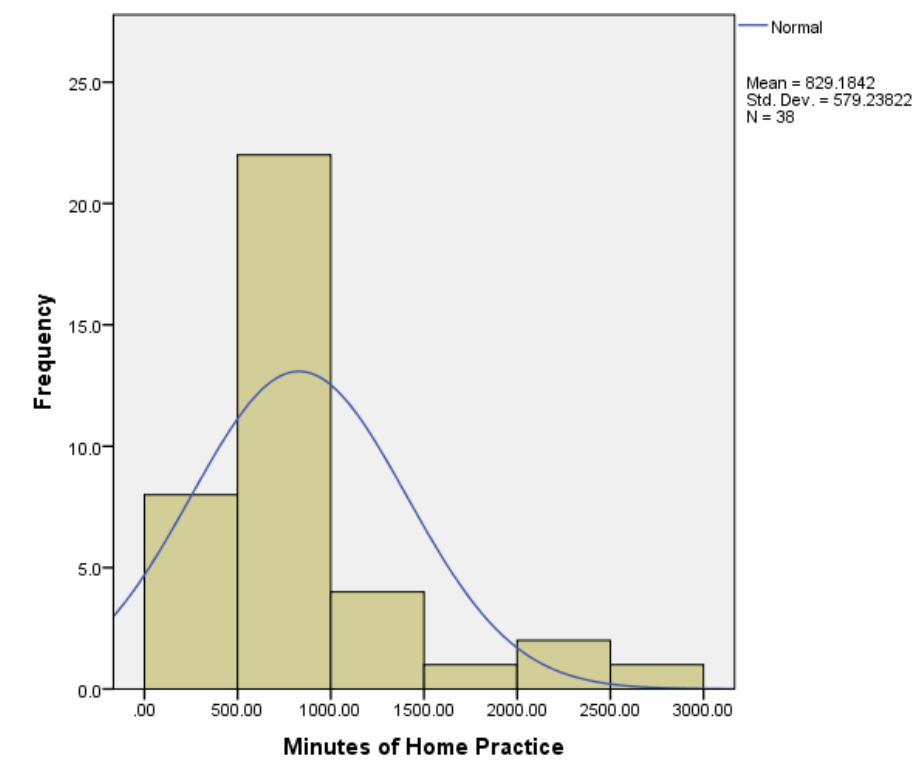

Figure 4. Histogram of individual differences in program-specific dose, measured as minutes of program attendance among teachers randomized to mindfulness condition. 


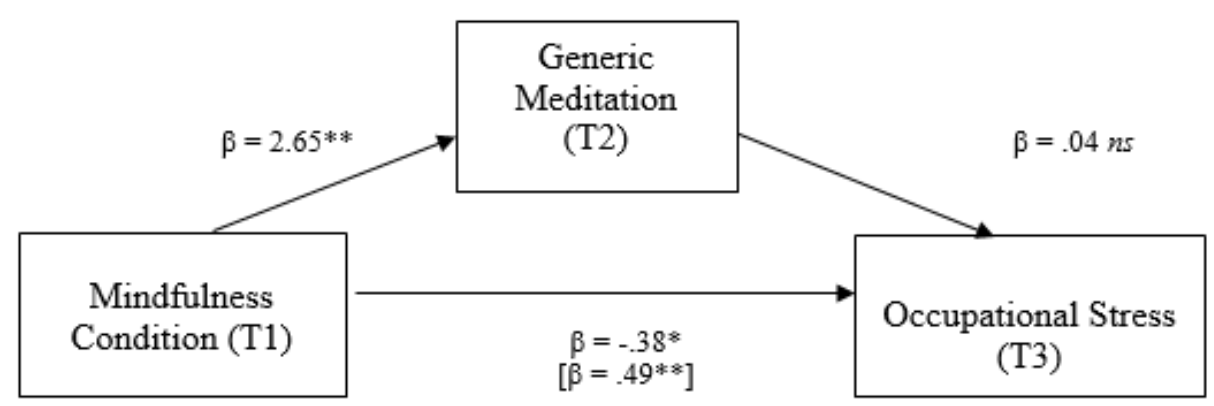

Figure 5. Test for mediation of intervention condition on teachers' occupational stress at followup (T3) by teachers' meditation frequency at post-program (T2). " $p<.05, * *_{p}<.001$.

Control Group $=$ "1", MT Group $=$ "2".

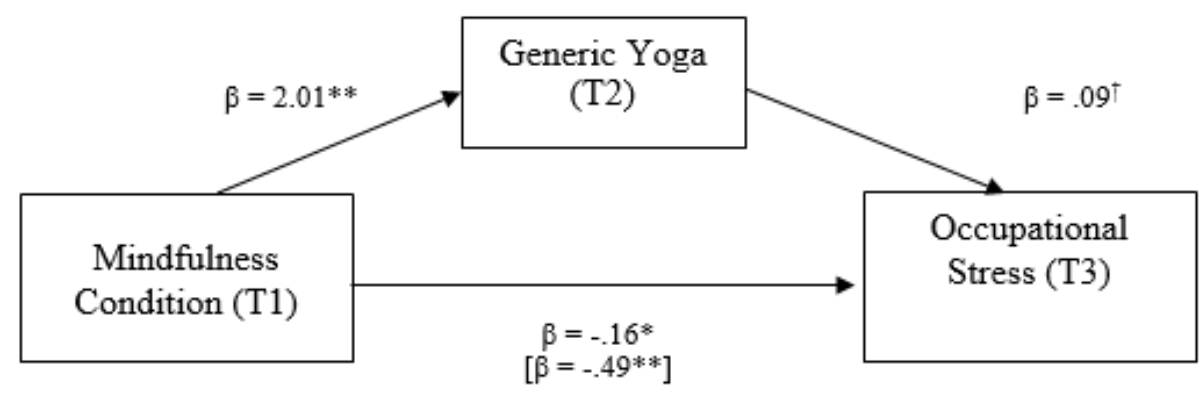

Figure 6. Test for mediation of intervention condition on teachers' symptoms of occupational stress at follow-up (T3) by teachers' mindful movement at post-program (T2). ${ }^{\dagger} p<.10,{ }^{*} p<.05$, $* * p<.001$.

Control Group $=" 1 "$, MT Group $=" 2 "$. 


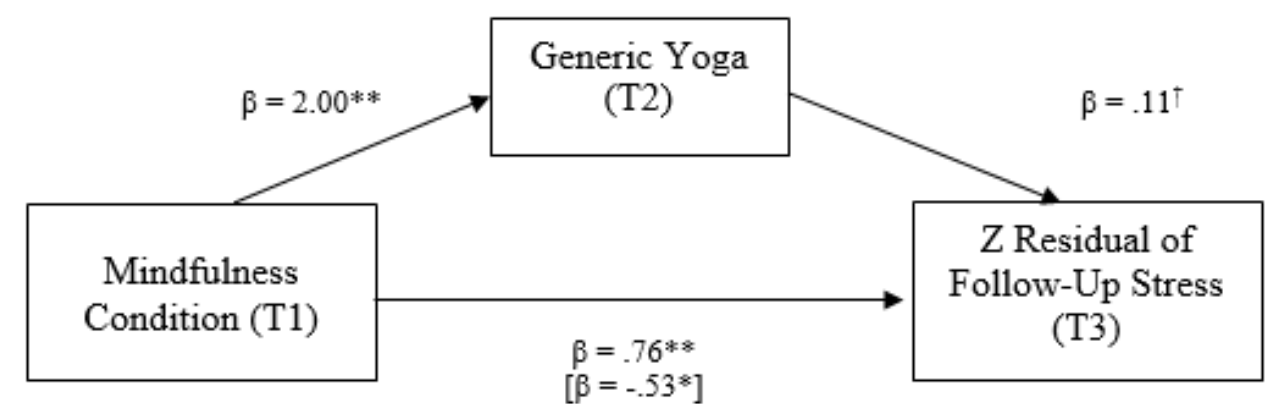

Figure 7. Test for mediation of intervention condition on teachers' symptoms of occupational stress at follow-up (T3), controlling for baseline occupational stress, by teachers' mindful movement at post-program (T2). ${ }^{\dagger} p<.10,{ }^{*} p<.05, * * p<.001$.

Control Group $=" 1 "$, MT Group $=" 2 "$. 


\section{References}

Baer, R.A., Smith, G.T., Hopkins, J., Krietemeyer, J. \& Toney, L. (2006). Using selfreport assessment methods to explore facets of mindfulness. Assessment, 13, 2745.

Baron, R. M., \& Kenny, D. A. (1986). The moderator-mediator variable distinction in social psychological research: Conceptual, strategic, and statistical considerations. Journal of personality and social psychology, 51(6), 1173.

Benn, R., Akiva, T., Arel, S., \& Roeser, R. W. (2012). Mindfulness training effects for parents and educators of children with special needs. Developmental psychology, 48(5), 1476.

Berger, B. G., \& Owen, D. R. (1988). Stress reduction and mood enhancement in four exercise modes: Swimming, body conditioning, hatha yoga, and fencing. Research quarterly for exercise and sport, 59(2), 148-159.

Biegel, G. M., Brown, K. W., Shapiro, S. L., \& Schubert, C. M. (2009). Mindfulnessbased stress reduction for the treatment of adolescent psychiatric outpatients: A randomized clinical trial. Journal of consulting and clinical psychology, 77(5), 855.

Bishop, S. R., Lau, M., Shapiro, S., Carlson, L., Anderson, N. D., Carmody, J., ... \& Devins, G. (2004). Mindfulness: A proposed operational definition. Clinical psychology: Science and practice, 11(3), 230-241. 
Blumenfeld, P. C., Mergendoller, J. R., \& Swarthout, D. W. (1987). Task as a heuristic for understanding student learning and motivation. Journal of curriculum studies, 19(2), 135-148.

Blumenfeld, P. C., Soloway, E., Marx, R. W., Krajcik, J. S., Guzdial, M., \& Palincsar, A. (1991). Motivating project-based learning: Sustaining the doing, supporting the learning. Educational psychologist, 26(3-4), 369-398.

Brown, A. L., \& Cocking, R. R. (2000). How people learn (pp. 285-348). J. D. Bransford (Ed.). Washington, DC: National Academy Press.

Brown, A. L., \& Cocking, R. R. (2000). How people learn (pp. 285-348). J. D. Bransford (Ed.). Washington, DC: National Academy Press.

Brown, K. W., Ryan, R. W., (2003). The benefits of being present: Mindfulness and its role in psychological well-being. Journal of Personality and Social Psychology, 84(4), 822848 .

Burchinal, M., Xue, Y., Tarullo, L., Zaslow, M., Tien, H., Auger, A., Cavadel, E., Mashburn, A., Martinez-Beck, I. (in press).

Caplan, R. D., Cobb, S., French Jr, J. R., Harrison, R. V., \& Pinneau Jr, S. R. (1975). Job demands and worker health: Main effects and occupational differences.

Carmody, J., \& Baer, R. A. (2008). Relationships between mindfulness practice and levels of mindfulness, medical and psychological symptoms and well-being in a 
mindfulness-based stress reduction program. Journal of behavioral medicine, 31(1), 23-33.

Carson, J. W., Carson, K. M., Gil, K. M., \& Baucom, D. H. (2004). Mindfulness-based relationship enhancement. Behavior Therapy, 35(3), 471-494.

Cecil, M. A., \& Forman, S. G. (1990). Effects of stress inoculation training and coworker support groups on teachers' stress. Journal of School Psychology, 28(2), 105-118.

Chambers, R., Gullone, E., \& Allen, N. B. (2009). Mindful emotion regulation: An integrative review. Clinical psychology review, 29(6), 560-572.

Chaplain, R. P. (2008). Stress and psychological distress among trainee secondary teachers in England. Educational Psychology, 28(2), 195-209.

Cheek, J. R., Bradley, L. J., Parr, G., \& Lan, W. (2003). Using music therapy techniques to treat teacher burnout. Journal of Mental Health Counseling, 25(3), 204-217.

Chiesa, A., \& Serretti, A. (2009). Mindfulness-based stress reduction for stress management in healthy people: a review and meta-analysis. The journal of alternative and complementary medicine, 15(5), 593-600.

Cohen, J. (1988). Statistical power analysis for the behavioral sciences. Psychology Press.

Cullen, M. (2011). Mindfulness-based interventions: An emerging phenomenon. Mindfulness, 2(3), 186-193. 
Darling-Hammond, L. (2006). Constructing $21^{\text {st }}$ - century teacher education. Journal of Teacher Education, 57(3), 300 - 314.

Daubenmier, J., Lin, J., Blackburn, E., Hecht, F. M., Kristeller, J., Maninger, N., ... \& Epel, E. (2012). Changes in stress, eating, and metabolic factors are related to changes in telomerase activity in a randomized mindfulness intervention pilot study. Psychoneuroendocrinology, 37(7), 917-928.

Davidson, R. J., Kabat-Zinn, J., Schumacher, J., Rosenkranz, M., Muller, D., Santorelli, S. F., ... \& Sheridan, J. F. (2003). Alterations in brain and immune function produced by mindfulness meditation. Psychosomatic medicine, 65(4), 564-570.

Davidson, R. J., \& Lutz, A. (2007). Buddha's brain: Neuroplasticity and meditation. IEEE Signal Processing Magazine, 172 -174, 176.

de Vibe, M., Solhaug, I., Tyssen, R., Friborg, O., Rosenvinge, J. H., Sørlie, T., ... \& Bjørndal, A. (2013). Does Personality Moderate the Effects of Mindfulness Training for Medical and Psychology Students?. Mindfulness, 1-9.

Durlak, J. A., \& DuPre, E. P. (2008). Implementation matters: A review of research on the influence of implementation on program outcomes and the factors affecting implementation. American journal of community psychology, 41(3-4), 327-350.

Ericsson, K. A., \& Charness, N. (1994). Expert performance: Its structure and acquisition. American psychologist, 49(8), 725. 
Farber, B., Ascher, C. (1991). Urban school restructuring and teacher burnout. New York, NY: ERIC Clearinghouse on Urban Education.

Farber, P. (1999). Teaching and its traditions. Philosophy of Education, 226 - 229.

Flook, L., Goldberg, S. B., Pinger, L., Bonus, K., \& Davidson, R. J. (2013). Mindfulness for Teachers: A Pilot Study to Assess Effects on Stress, Burnout, and Teaching Efficacy. Mind, Brain, and Education, 7(3), 182-195.

Folkman, S., Lazarus, R. S., Dunkel-Schetter, C., DeLongis, A., Gruen, R. J. (1986). Dynamics of a stressful encounter: Cognitive appraisal, coping, and encounter outcomes. Journal of Personality and Social Psychology, 50(5), 992 - 1003.

Fox, K., Borer, J. S., Camm, A. J., Danchin, N., Ferrari, R., Sendon, J. L. L., ... The Heart Rate Working Group. (2007). Resting heart rate in cardiovascular disease. Journal of the American College of Cardiology, 50, 823 - 830.

Franco, C., Mañas, I. M., Cangas, A. J., San Pedro, E. M., \& Gámez, A. G. (2010). Reducing teachers' psychological distress through a mindfulness training program. Spanish journal of psychology, 13(2), 655-666.

Frank, J. L., Reibel, D., Broderick, P., Cantrell, T., \& Metz, S. (2013). The Effectiveness of Mindfulness-Based Stress Reduction on Educator Stress and Well-Being: Results from a Pilot Study. Mindfulness, 1-9. 
Friedman, I. A. (1996). Multiple pathways to burnout: Cognitive and emotional scenarios in teacher burnout. Anxiety, Stress, and coping, 9(3), 245-259.

Geschwind, N., Peeters, F., Huibers, M., van Os, J., \& Wichers, M. (2012). Efficacy of mindfulness-based cognitive therapy in relation to prior history of depression: randomised controlled trial. The British Journal of Psychiatry, 201(4), 320-325.

Gold, E., Smith, A., Hopper, I., Herne, D., Tansey, G., \& Hulland, C. (2010). Mindfulness-based stress reduction (MBSR) for primary school teachers. Journal of Child and Family Studies, 19(2), 184-189.

Gold, Y., Roth, R. A. (1993). Teachers managing stress and preventing burnout. The professional health solution. UK: The Falmer Press.

Gross, C. R., Kreitzer, M. J., Thomas, W., Reilly-Spong, M., Cramer-Bornemann, M., Nyman, J. A., ... \& Ibrahim, H. N. (2010). Mindfulness-based stress reduction for solid organ transplant recipients: a randomized controlled trial. Alternative therapies in health and medicine, 16(5), 30.

Grossman, P., Niemann, L., Schmidt, S., \& Walach, H. (2004). Mindfulness-based stress reduction and health benefits: A meta-analysis. Journal of psychosomatic research, 57(1), 35-43.

Guardino, C. M., Dunkel Schetter, C., Bower, J. E., Lu, M. C., \& Smalley, S. L. (2013). Randomised controlled pilot trial of mindfulness training for stress reduction during pregnancy. Psychology \& health, (ahead-of-print), 1-16. 
Guglielmi, R. S., \& Tatrow, K. (1998). Occupational stress, burnout, and health in teachers: A methodological and theoretical analysis. Review of educational research, 68(1), 61-99.

Hoffman, C. J., Ersser, S. J., Hopkinson, J. B., Nicholls, P. G., Harrington, J. E., \& Thomas, P. W. (2012). Effectiveness of mindfulness-based stress reduction in mood, breast-and endocrine-related quality of life, and well-being in stage 0 to III breast cancer: a randomized, controlled trial. Journal of Clinical Oncology, 30(12), 1335-1342.

Hou, R. J., Wong, S. S., Yip, B. K., Hung, A. T., Lo, H. M., Chan, P. H., ... \& Ma, S. H. (2013). The Effects of Mindfulness-Based Stress Reduction Program on the Mental Health of Family Caregivers: A Randomized Controlled Trial. Psychotherapy and psychosomatics, 83(1), 45-53.

Ingersoll, R. M. (2001). Teacher turnover and teacher shortages: An organizational analysis. American Educational Research Journal, 38(3), 499 - 534).

Jain, S., Shapiro, S. L., Swanick, S., Roesch, S. C., Mills, P. J., \& Schwartz, G. E. (2007). A randomized controlled trial of mindfulness meditation versus relaxation training: Effects on distress, positive states of mind, rumination, and distraction. Annals of Behavioral Medicine, 33(1), 11-21.

Jalongo, M. R., \& Heider, K. (2006). Editorial teacher attrition: An issue of national concern. Early Childhood Education Journal, 33, 379-380. 
Jennings, P. A., Frank, J. L., Snowberg, K. E., Coccia, M. A., \& Greenberg, M. T.

(2013). Improving classroom learning environments by Cultivating Awareness and Resilience in Education (CARE): Results of a randomized controlled trial. School Psychology Quarterly, 28(4), 374.

Jennings, P. A., Greenberg, M. T. (2009). The prosocial classroom: Teacher social and emotional competence in relation to student and classroom outcomes. Review of Educational Research, 79(1), $491-525$.

Jennings, P., Lantieri, L., \& Roeser, R. W. (2012). Supporting Educational Goals through Cultivating Mindfulness. Handbook of prosocial education, 1, 371.

Jennings, P. A., Snowberg, K. E., Coccia, M. A., \& Greenberg, M. T. (2011). Improving Classroom Learning Environments by Cultivating Awareness and Resilience in Education (CARE): Results of Two Pilot Studies. Journal of Classroom Interaction, 46(1).

Johnson, S., Cooper, C., Cartwright, S., Donald, I., Taylor, P., \& Millet, C. (2005). The experience of work-related stress across occupations. Journal of managerial psychology, 20(2), 178-187.

Kabat-Zinn, J. (1990). Full catastrophe living: Using the wisdom of your mind and body to face stress, pain, and illness. New York: Delacorte. 
Karasek, R. A. (1979). Job demands, job decision latitude, and mental strain: Implications for a job redesign. Administrative Science Quarterly, 24(2), 285 308.

Kemeny, M. E., Foltz, C., Cavanagh, J. F., Cullen, M., Giese-Davis, J., Jennings, P., Rosenberg, E. L., Gillath, O., Shaver, P. R., Wallace, B.A., \& Ekman, P. (2012). Contemplative/emotion training reduces negative emotional behavior and promotes prosocial responses. Emotion, 12(2), 338.

Klassen, R. M., \& Chiu, M. M. (2010). Effects on teachers' self-efficacy and job satisfaction: Teacher gender, years of experience, and job stress. Journal of Educational Psychology, 102(3), 741.

Kyriacou, C. (2001). Teacher stress: Directions for future research. Educational review, 53(1), 27-35.

Lambert, R. G., \& McCarthy, C. J., Eds. (2006). Understanding teacher stress in an era of accountability (Vol. 3). Greenwich, CT: Information Age.

Lambert, R. G., McCarthy, C., O'Donnell, M., \& Wang, C. (2009). Measuring elementary teacher stress and coping in the classroom: Validity evidence for the classroom appraisal of resources and demands. Psychology in the Schools, 46(10), 973-988.

Lazarus, R. S. (2006). Stress and emotion: A new synthesis. Springer Publishing Company.

Lazarus, R. S., \& Folkman, S. (1984). Stress. Appraisal and Coping, New York. 
Lengacher, C. A., Johnson-Mallard, V., Post-White, J., Moscoso, M. S., Jacobsen, P. B., Klein, T. W., ... \& Kip, K. E. (2009). Randomized controlled trial of mindfulnessbased stress reduction (MBSR) for survivors of breast cancer. PsychoOncology, 18(12), 1261-1272.

Lumsden, L. (1998). Teacher morale. Eric Digest, 120.

Maslach, C., \& Jackson, S. E. (1981). The measurement of experienced burnout. Journal of Organizational Behavior, 2(2), 99-113.

Maslach, C., Schaufeli, W. B., \& Leiter, M. P. (2001). Job burnout. Annual review of psychology, 52(1), 397-422.

Montgomery, C., \& Rupp, A. A. (2005). A meta-analysis exploring the diverse causes and effects of stress in teachers. Canadian Journal of Education, 28, 458-486.

NCTAF (2007). The high cost of teacher turnover. Washington, DC.

Nyklíček, I., \& Kuijpers, K. F. (2008). Effects of mindfulness-based stress reduction intervention on psychological well-being and quality of life: is increased mindfulness indeed the mechanism?. Annals of Behavioral Medicine,35(3), 331340.

Perloff, D., Grim, C., Flack, J., Frohlich, E. D., Hill, M., McDonald, M., \& Morgenstern, B. Z. (1993). Human blood pressure determination by sphygmomanometer. Circulation, 88, $2460-2470$. 
Peters, R. K., Benson, H., \& Porter, D. (1977). Daily relaxation response breaks in a working population: I. Effects on self-reported measures of health, performance, and well-being. American Journal of Public Health, 67(10), 946-953.

Poulin, P. A., Mackenzie, C. S., Soloway, G., \& Karayolas, E. (2008). Mindfulness training as an evidenced-based approach to reducing stress and promoting wellbeing among human services professionals. International Journal of Health Promotion and Education, 46(2), 72-80.

Preacher, K. J., \& Hayes, A. F. (2004). SPSS and SAS procedures for estimating indirect effects in simple mediation models. Behavior Research Methods, Instruments, \& Computers, 36(4), 717-731.

Richardson, K. M., \& Rothstein, H. R. (2008). Effects of occupational stress management intervention programs: a meta-analysis. Journal of occupational health psychology, 13(1), 69.

Roeser, R.W., \& Midgley, C.M. (1997). Teachers' views of aspects of student mental health. Elementary School Journal, 98, 115-133.

Roeser, R. W., Schonert-Reichl, K. A., Jha, A., Cullen, M., Wallace, L., Wilensky, R., Oberle, E., Thomson, K., Taylor, C., Harrison, J. (2013). Mindfulness training and reductions in teacher stress and burnout: Results from two randomized, waitlist-control field trials. Journal of Educational Psychology. 
Roeser, R. W., Skinner, E., Beers, J., \& Jennings, P. A. (2012). Mindfulness Training and Teachers' Professional Development: An Emerging Area of Research and Practice. Child development perspectives, 6(2), 167-173.

Rudow, B., Vandenberghe, R., Huberman, A. M. (1999). Stress and burnout in the teaching profession: European studies, issues, and research perspectives. Understanding and preventing teacher burnout: A sourcebook of international research and practice. $(33-58)$. New York, NY: Cambridge University Press.

Sephton, S. E., Salmon, P., Weissbecker, I., Ulmer, C., Floyd, A., Hoover, K., \& Studts, J. L. (2007). Mindfulness meditation alleviates depressive symptoms in women with fibromyalgia: results of a randomized clinical trial. Arthritis Care \& Research, 57(1), 77-85.

Skinner, E. A., Edge, K., Altman, J., \& Sherwood, H. (2003). Searching for the structure of coping: a review and critique of category systems for classifying ways of coping. Psychological bulletin, 129(2), 216.

Smylie, M. A., Perry, G. S. (2005). Restructuring schools for improving teaching. Fundamental Change, 306 - 335.

Sobel, M. E. (1982). Asymptotic confidence intervals for indirect effects in structural equation models. Sociological methodology, 13(1982), 290-312.

Speca, M., Carlson, L. E., Goodey, E., \& Angen, M. (2000). A randomized, wait-list controlled clinical trial: the effect of a mindfulness meditation-based stress 
reduction program on mood and symptoms of stress in cancer outpatients. Psychosomatic medicine, 62(5), 613-622.

Strunk, K. O., Robinson, J. P. (2006). Oh, won't you stay: A multilevel analysis of the difficulties in retaining qualified teachers. Peabody Journal of Education, 81(4), $65-94$.

Taylor, C., Harrison, J., Roeser, R. W. (2012). Examining the mechanisms of stress reduction in a mindfulness-training program for teachers: mindfulness, selfcompassion, efficacy and coping. AERA.

Thoits, P. A. (2010). Stress and health major findings and policy implications. Journal of Health and Social Behavior, 51(1 suppl), S41-S53.

Vettese, L. C., Toneatto, T., Stea, J. N., Nguyen, L., \& Wang, J. J. (2009). Do mindfulness meditation participants do their homework? And does it make a difference? A review of the empirical evidence. Journal of Cognitive Psychotherapy, 23(3), 198-225.

Vieten, C., \& Astin, J. (2008). Effects of a mindfulness-based intervention during pregnancy on prenatal stress and mood: results of a pilot study. Archives of women's mental health, 11(1), 67-74.

Virgili, M. (2013). Mindfulness-Based Interventions Reduce Psychological Distress in Working Adults: a Meta-Analysis of Intervention Studies. Mindfulness, 1-12. 
Wagner, A. K., Soumerai, S. B., Zhang, F., \& Ross-Degnan, D. (2002). Segmented regression analysis of interrupted time series studies in medication use research. Journal of clinical pharmacy and therapeutics, 27(4), 299-309.

Weitzman, E. D., Fukushima, D., Nogeire, C., Roffwarg, H., Gallagher, T. F., \& Hellman, L. (1971). Twenty-four hour pattern of the episodic secretion of cortisol in normal subjects. Journal of Clinical Endocrinology \& Metabolism, 33, 14-22.

Winzelberg, A. J., \& Luskin, F. M. (1999). The effect of a meditation training in stress levels in secondary school teachers. Stress and Health, 15(2), 69-77.

Young, S. (2011). Natural Pain Relief: How to Soothe \& Dissolve Physical Pain with Mindfulness [With CD (Audio)]. Sounds True. 


\section{Appendix: Measures}

\section{Dose}

Do you have a meditation practice? (please check one)

$\underline{0 \quad \text { No }} \quad 1 \ldots$ Yes

If no, please skip to next page. If yes, please continue with the questions below.

How often do you meditate now? (check one)

1 Less than once a year

$\underline{2}$ About once or twice a year

3 About once a month

$\underline{4} \quad$ Nearly every week

$\underline{5 \quad \text { Several times a week }}$

$\underline{6} \quad$ Nearly every day

$\underline{7} \quad$ Every day

$\underline{8} \quad$ Several times a day

Do you have a yoga or disciplined movement practice like Tai Chi? (please check one)

${ }$ No $\quad$ Yes

If no, please skip to next page. If yes, please continue with the questions below.

How often do you practice your yoga / movement practice now? (check one)

1 Less than once a year

$\underline{2}$ About once or twice a year 
About once a month

$\underline{4 \quad \text { Nearly every week }}$

$\underline{5 \quad S e v e r a l ~ t i m e s ~ a ~ w e e k ~}$

$\underline{6 \quad \text { Nearly every day }}$

$\underline{7} \quad$ Every day

$\underline{8 \quad \text { Several times a day }}$

\section{Burnout}

Maslach Burnout Inventory:

Please read the statements below and select the number that indicates how often you feel this way.

1. feel emotionally drained from your work?

2. feel used up at the end of the work day?

3. feel fatigued when you get up in the morning and have to face another day on the job?

4. easily understand how your students are feeling about things?

5. feel that you treat some students as if they were impersonal objects?

6. feel that working with people all day is really a strain?

7. deal very effectively with the problems of your students?

8. feel burned out from your work?

9. feel like you are positively influencing other people's lives through your work? 
10. feel like you've become more callous toward people since you took this job?

11. worry that this job is hardening you emotionally?

12. feel very energetic at work?

13. feel frustrated by your job?

14. feel you're working too hard on your job?

15. feel you don't really care what happens to some students?

16. feel working with people directly puts too much stress on you?

17. create a relaxed classroom atmosphere with your students?

18. feel exhilarated after working closely with your students?

19. feel you have accomplished many worthwhile things in this job?

20. feel like you're at the end of your rope?

21. deal with emotional problems in the classroom very calmly?

feel students blame you for some of their problems? 